\title{
Assimilation of atmospheric methane products into the MACC-II system: from SCIAMACHY to TANSO and IASI
}

\author{
S. Massart ${ }^{1}$, A. Agusti-Panareda ${ }^{1}$, I. Aben ${ }^{2}$, A. Butz ${ }^{3}$, F. Chevallier ${ }^{4}$, C. Crevosier ${ }^{5}$, R. Engelen ${ }^{1}$, C. Frankenberg ${ }^{6}$, \\ and O. Hasekamp ${ }^{2}$ \\ ${ }^{1}$ European Centre for Medium-Range Weather Forecasts, Reading, UK \\ ${ }^{2}$ SRON Netherlands Institute for Space Research, Utrecht, the Netherlands \\ ${ }^{3}$ Karlsruhe Institute of Technology, Karlsruhe, Germany \\ ${ }^{4}$ Laboratoire des Sciences du Climat et de l'Environnement, CEA-CNRS-UVSQ, UMR8212, IPSL, Gif-sur-Yvette, France \\ ${ }^{5}$ Laboratoire de Météorologie Dynamique/IPSL/CNRS, Ecole Polytechnique, Palaiseau, France \\ ${ }^{6}$ Jet Propulsion Laboratory, Pasadena, USA
}

Correspondence to: S. Massart (sebastien.massart@ecmwf.int)

Received: 2 December 2013 - Published in Atmos. Chem. Phys. Discuss.: 27 January 2014

Revised: 1 May 2014 - Accepted: 17 May 2014 - Published: 23 June 2014

\begin{abstract}
The Monitoring Atmospheric Composition and Climate Interim Implementation (MACC-II) delayed-mode (DM) system has been producing an atmospheric methane $\left(\mathrm{CH}_{4}\right)$ analysis 6 months behind real time since June 2009 . This analysis used to rely on the assimilation of the $\mathrm{CH}_{4}$ product from the SCanning Imaging Absorption spectroMeter for Atmospheric CHartographY (SCIAMACHY) instrument onboard Envisat. Recently the Laboratoire de Météorologie Dynamique (LMD) $\mathrm{CH}_{4}$ products from the Infrared Atmospheric Sounding Interferometer (IASI) and the SRON Netherlands Institute for Space Research $\mathrm{CH}_{4}$ products from the Thermal And Near-infrared Sensor for carbon Observation (TANSO) were added to the DM system. With the loss of Envisat in April 2012, the DM system now has to rely on the assimilation of methane data from TANSO and IASI. This paper documents the impact of this change in the observing system on the methane tropospheric analysis. It is based on four experiments: one free run and three analyses from respectively the assimilation of SCIAMACHY,

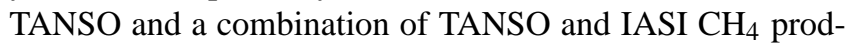
ucts in the MACC-II system. The period between December 2010 and April 2012 is studied. The SCIAMACHY experiment globally underestimates the tropospheric methane by 35 part per billion (ppb) compared to the HIAPER Pole-toPole Observations (HIPPO) data and by $28 \mathrm{ppb}$ compared the Total Carbon Column Observing Network (TCCON) data, while the free run presents an underestimation of $5 \mathrm{ppb}$ and
\end{abstract}

$1 \mathrm{ppb}$ against the same HIPPO and TCCON data, respectively. The assimilated TANSO product changed in October 2011 from version v.1 to version v.2.0. The analysis of version v.1 globally underestimates the tropospheric methane by $18 \mathrm{ppb}$ compared to the HIPPO data and by $15 \mathrm{ppb}$ compared to the TCCON data. In contrast, the analysis of version v.2.0 globally overestimates the column by $3 \mathrm{ppb}$. When the high density IASI data are added in the tropical region between $30^{\circ} \mathrm{N}$ and $30^{\circ} \mathrm{S}$, their impact is mainly positive but more pronounced and effective when combined with version v.2.0 of the TANSO products. The resulting analysis globally underestimates the column-averaged dry-air mole fractions of methane $\left(\mathrm{xCH}_{4}\right)$ just under $1 \mathrm{ppb}$ on average compared to the TCCON data, whereas in the tropics it overestimates $\mathrm{xCH}_{4}$ by about $3 \mathrm{ppb}$. The random error is estimated to be less than $7 \mathrm{ppb}$ when compared to TCCON data.

\section{Introduction}

Methane $\left(\mathrm{CH}_{4}\right)$ is well known to be the third most important greenhouse gas in the atmosphere (after water vapour and $\mathrm{CO}_{2}$ ), accounting for $17 \pm 1.8 \%$ of the enhanced greenhouse effect (Myhre et al., 2013). It also plays a key role in tropospheric chemistry and, therefore, in air quality issues through oxidation by hydroxyl $(\mathrm{OH})$ radicals. Methane fraction has increased substantially in the atmosphere since the 
pre-industrial period. As an example, atmospheric $\mathrm{CH}_{4}$ concentrations reached $1813 \pm 2$ parts per billion $(\mathrm{ppb})$ in 2011 (WMO, 2012), whereas they varied between 350 and $850 \mathrm{ppb}$ over the past $650000 \mathrm{yr}$ (Spahni et al., 2005). Etheridge et al. (1992) show that the increase was exponential between 1850 and the late 1970s, with values starting from $830 \mathrm{ppb}$ and reaching $1500 \mathrm{ppb}$. Their study is based on the reconstruction of an atmospheric $\mathrm{CH}_{4}$ mixing ratio from air trapped in polar ice cores and compacted snow. Keeping track of the evolution of atmospheric $\mathrm{CH}_{4}$ has become easier since the early 1980s with the development of surface-based networks that directly measure $\mathrm{CH}_{4}$ in the atmosphere. Since then the networks have improved with increasing coverage and intercalibration. The analysis of the collected data from these networks allowed, for example, Kirschke et al. (2013) to estimate the changes in the annual growth rate of the global atmospheric $\mathrm{CH}_{4}$ concentration since 1980 . They show, in particular, that the $\mathrm{CH}_{4}$ atmospheric growth rate was estimated to be more than $10 \mathrm{ppbyr}^{-1}$ in 1998 and less than zero in 2001, 2004 and 2005. Since 2006, the growth rate has started to increase again. Moreover, the annual growth rate as well as its inter-annual variability have strong regional variation, as shown by Dlugokencky et al. (2009). This argues for the continuous global monitoring of the atmospheric $\mathrm{CH}_{4}$. More recently, in addition to surface networks, monitoring can benefit from remotely sensed measurements of atmospheric $\mathrm{CH}_{4}$ columns retrieved from the surface or from space.

Observation of $\mathrm{CH}_{4}$ and other greenhouse gases from space is relatively recent compared to the observation of other minor constituents of the atmosphere. Monitoring atmospheric composition from space started with ozone in 1978 when the Nimbus 7 satellite was launched. Nimbus 7 carried the first Total Ozone Mapping Spectrometer (TOMS) instrument that helped to confirm the Antarctic ozone hole discovered by Joe Farman and colleagues in the early 1980s (Farman et al., 1985). TOMS has since then flown on several other satellites and almost continuously monitored the atmospheric ozone column (McPeters and Labow, 1996). TOMS was the precursor of a new generation of instruments launched since the mid-1990s. Some of these instruments were designed to continue the monitoring of ozone and some were designed to also measure other atmospheric constituents of interest. These constituents were selected for their link with ozone (especially the gases that are involved in its depletion) or for their potential impact on Numerical Weather Prediction (NWP) as, under some assumptions, the assimilation of chemical constituent observations can bring information on wind fields (Daley, 1995). Moreover, NWP systems assimilate instrument radiances sensitive not only to temperature but also to atmospheric constituents (Engelen and Bauer, 2014).

With the arrival of atmospheric composition measurements from space, it became possible to emulate NWP by providing chemical forecasts and analyses of chemical constituents based on chemical models and data assimilation techniques. The launch of the Envisat satellite in 2002 was a breakthrough in the atmospheric composition observing system (Lahoz et al., 2007). The payload included SCIAMACHY (SCanning Imaging Absorption spectroMeter for Atmospheric CHartographY), the first instrument in space from which column products of $\mathrm{CH}_{4}$ were derived. Today, $\mathrm{CH}_{4}$ columns can be retrieved from the Tropospheric Emission Spectrometer (TES) instrument aboard NASA's Aura satellite (launched in 2004), from the Infrared Atmospheric Sounding Interferometer (IASI) instrument aboard the first European meteorological polar-orbiting satellites, MetOpA (launched in 2006) or the Thermal And Near-infrared Sensor for carbon Observation (TANSO) aboard the Greenhouse gases Observing Satellite (GOSAT, launched in 2009). SCIAMACHY and TANSO measurements are in the nearinfrared (NIR) while TES and IASI measurements are in the thermal infrared (TIR). NIR methane retrievals are sensitive to the entire tropospheric column, but due to their dependence on reflected sunlight, observations are unavailable at night. TIR methane retrievals can be performed day and night, over land and ocean, and for partly cloudy scenes, but they have limited sensitivity to the lower troposphere (due to the lack of thermal contrast) and their precision is limited mainly by uncertainties in atmospheric temperature and surface emissivity. The combination of all these measurements of atmospheric $\mathrm{CH}_{4}$ columns from space are complementary to surface observations to monitor atmospheric $\mathrm{CH}_{4}$, although they provide only vertically integrated information, which is also associated with notable uncertainties.

Data assimilation provides the ability to combine all the information from different instruments and observing networks with a model in an optimal way. This study presents one of the two data assimilation products provided by the Monitoring Atmospheric Composition and Climate Interim Implementation (MACC-II) project and using $\mathrm{CH}_{4}$ measurement from space. The first product combines satellite measurements of $\mathrm{CH}_{4}$ with inverse modelling in order to optimise the surface sources and sinks of $\mathrm{CH}_{4}$ (Bergamaschi et al., 2009). The second product combines the satellite measurements with a forward transport model in order to monitor tropospheric $\mathrm{CH}_{4}$. In this paper, we will focus on this second product. It uses the European Centre for Medium-Range Weather Forecasts (ECMWF) Integrated Forecasting System (IFS). Methane satellite measurements and all the other operational meteorological data are assimilated in the IFS to produce the best estimate of the atmospheric state, referred to hereafter as the analysis. However, unlike most of the data assimilated in NWP, $\mathrm{CH}_{4}$ data are not yet available in near real time, mainly due to their partial reliance on auxiliary data. As a consequence, the assimilation system is run with a 6-month lag in a so-called "delayed mode" (DM).

The MACC-II DM system started producing a $\mathrm{CH}_{4}$ analysis from 1 June 2009 onwards. This analysis was initially based on the $\mathrm{CH}_{4}$ product from SCIAMACHY provided by the SRON Netherlands Institute for Space Research 
in collaboration with the Jet Propulsion Laboratory (JPL, Frankenberg et al., 2005) and the version v00.50 $\mathrm{CH}_{4}$ product from TANSO provided by the Japan National Institute for Environmental Studies (NIES). This TANSO product was not mature enough at this time and its assimilation increased the bias and the variability of the analysis. Therefore the SCIAMACHY $\mathrm{CH}_{4}$ product remained for a while the only $\mathrm{CH}_{4}$ product assimilated in the DM system. With the loss of Envisat in April 2012, the methane analysis of the DM system had to rely on other instruments. To continue the monitoring of the atmospheric $\mathrm{CH}_{4}$ with the DM system, TANSO and IASI $\mathrm{CH}_{4}$ products were included in the assimilation system. TANSO has similar characteristics as SCIAMACHY but provides about 10 times fewer data than SCIAMACHY during a given assimilation window. Its data are nevertheless more accurate than those from SCIAMACHY. Since our first attempt at assimilating TANSO data, several retrieval algorithms processing the TANSO data have been developed by several teams (Parker et al., 2011; Schepers et al., 2012; Yoshida et al., 2013). The MACC-II product is jointly developed by SRON and the Karlsruhe Institute of Technology (KIT, Butz et al., 2010). As a TIR sounder, IASI provides complementary information on the middle troposphere during day and night over land and over sea. The MACC-II IASI product is from the Laboratoire de Météorologie Dynamique (LMD). Currently the product can be used in the tropics only (Crevoisier et al., 2009). The assimilation of TES was not considered because its data cannot be assimilated into the DM system as it is not available within the expected 6-month latency period.

The aim of this paper is to document the impact of the assimilation of TANSO and IASI $\mathrm{CH}_{4}$ products compared to the assimilation of the SCIAMACHY product in order to determine how the change in the observing system would impact the DM analysis. Section 2 provides more details on the assimilated data and describes the assimilation system as well as the experiments we ran to assess the impact of each data set on the analysis. Section 3 presents the results of our assimilation experiments and their comparison with independent measurements of atmospheric $\mathrm{CH}_{4}$. The last section addresses the question of whether the combination of TANSO and IASI products is a good candidate for continuing the monitoring of methane in our analysis system.

\section{Analysis experiments}

For the period between November 2010 and April 2012 we ran three data assimilation experiments based on the following $\mathrm{CH}_{4}$ products: (1) SCIAMACHY; (2) TANSO; (3) TANSO and IASI. These experiments are referred hereafter to as SCIA, TANSO and IASI+TANSO, respectively (Fig. 1). To assess the impact of the assimilation of each product, we also ran an experiment for this period without the assimilation of $\mathrm{CH}_{4}$ observations. This experiment is referred to as free run FREE. The free run and the assimilation system are described in the following subsection. Then we present the three assimilated data sets. The last subsection details the experiments we ran.

\subsection{Analysis system}

The MACC-II greenhouse gases DM system is based on ECMWF IFS. It runs at a global horizontal resolution of T511 $\approx 40 \mathrm{~km})$ with 60 vertical levels from the surface up to $0.1 \mathrm{hPa}$. Because this horizontal resolution is too costly for long assimilation experiments, we chose in this study to keep the configuration of the DM system but to decrease the horizontal resolution to T255 ( $\approx 80 \mathrm{~km})$, which is sufficient for resolving the large-scale horizontal structures of the atmospheric $\mathrm{CH}_{4}$ fields

Based on the default IFS configuration, all the observations (operational and methane) are assimilated within the $12 \mathrm{~h}$ 4-D-Var window to constrain the meteorological variables as well as atmospheric $\mathrm{CH}_{4}$. Methane mass mixing ratio is directly transported within IFS as a tracer and is subject to fluxes and chemical sinks. Methane fluxes are prescribed in IFS using inventory and climatological data sets. These fluxes are consistent with those used as prior information in the $\mathrm{CH}_{4}$ flux inversions from Bergamaschi et al. (2009). The anthropogenic fluxes are from the EDGAR 4.2 database (Janssens-Maenhout et al., 2012) for the year 2008, i.e. the last available year. All the anthropogenic categories are based on annual mean values, except for rice, which has been modulated with the seasonal cycle from Matthews' monthly inventory for rice (Matthews et al., 1991). The wetland fluxes are from the Kaplan climatology described in Bergamaschi et al. (2007). The biomass burning emissions are from the MACC-II GFAS data set (Kaiser et al., 2012). The other sources/sinks include wild animals (Houweling et al., 1999), termites (Sanderson, 1996), oceans (Houweling et al., 1999; Lambert and Schmidt, 1993) and a soil sink (Ridgwell et al., 1999). For the chemical sink in the troposphere and the stratosphere, the climatological chemical loss rates from Bergamaschi et al. (2009) are used. These are based on $\mathrm{OH}$ fields optimised with methyl chloroform using the TM5 model (Krol et al., 2005) and prescribed concentrations of the stratospheric radicals using the 2-D photochemical Max Planck Institute model.

The background and observation error covariance matrices for the $\mathrm{CH}_{4}$ assimilation are specified as for all the IFS meteorological variables. The background error is derived from the National Meteorological Center (NMC) method (Parrish and Derber, 1992) and is set to be constant in time. Its standard deviation (diagonal of the covariance matrix) is about $20 \mathrm{ppb}$ in the troposphere and increases to a value of $150 \mathrm{ppb}$ at the surface. The correlations are constant over the whole domain, with a representative length scale of about $200 \mathrm{~km}$. The system does not account for the spatial or temporal correlation between the errors of the observations. The 


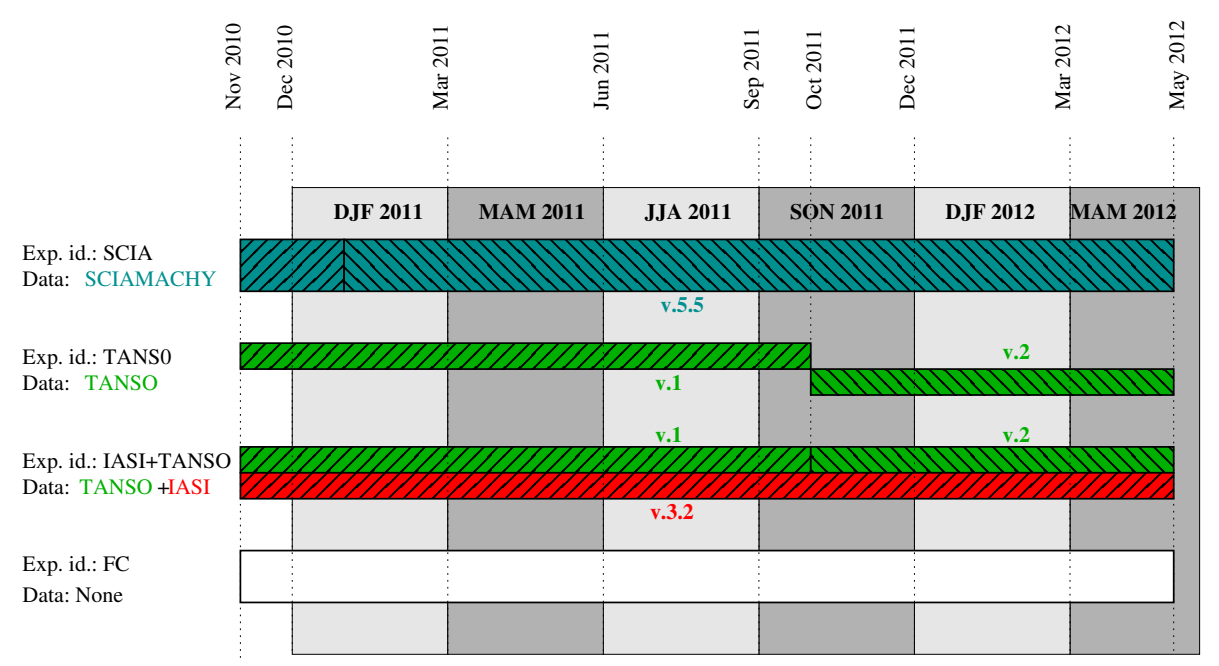

Figure 1. Configuration of the experiments. Each line represents an experiment and the box represents the timeline when the experiment was run. The name of the experiment is given by "Exp. Id.". The assimilated data is given by "Data". The text near the boxes is the version of the data that were assimilated.

observation error standard deviation is provided with the data and is specified later on for each used data set.

\subsection{Assimilated data}

The MACC-II DM system is able to assimilate various kinds of data sets like radiances or geophysical products with and without averaging kernels. For methane, the choice was made to assimilate retrieval products in order to lower the level of complexity compared to assimilating radiances.

For each $\mathrm{CH}_{4}$ product, we used the data at all the qualityflagged pixels of the instrument. Because the pixel size of the instruments is lower compared to the size of the model grid cells, we could have the situation of several observations per model grid cell during an assimilation window. The correlation between the observation errors should then be taken into account. To avoid this situation, we thinned the observations on a $1^{\circ} \times 1^{\circ}$ grid.

\subsubsection{SCIAMACHY}

SCIAMACHY measured the direct light from the Sun as well as the solar light reflected by the Earth. The difference provides information on the atmosphere through which the Earth-reflected light has passed, especially information on the concentration of trace gases and aerosols in the troposphere and stratosphere. SCIAMACHY measured the light between 240 and $1700 \mathrm{~nm}$, and in certain spectra between 2000 and $2400 \mathrm{~nm}$ at a moderate spectral resolution $(0.2$ to $0.5 \mathrm{~nm})$.

Envisat flew in a sun-synchronous polar orbit at an altitude of $790 \mathrm{~km}$. It orbited the Earth in about $101 \mathrm{~min}$ with a repeat cycle of 35 days. Along the orbits, SCIAMACHY used different observation modes: nadir, limb, and solar or lunar oc- cultation. For the nadir mode which is used in this study the swath was $960 \mathrm{~km}$. For the methane product, the pixel size on the ground was $30 \mathrm{~km}$ (along track) by $60 \mathrm{~km}$ (across track). Per $12 \mathrm{~h}$ assimilation window SCIAMACHY provided about $1200 \mathrm{CH}_{4}$ data points with a distribution as shown in Fig. 2. In autumn, the best observed places are the continents over a large tropical band. For example, over Australia more than 10 observations per model grid point are provided for the whole month of October 2011. North Africa is also well observed, with several model grid points having about 25 observations. Oceans south of $30^{\circ} \mathrm{S}$ are better observed than other oceans, but they have on average less than 5 observations per month. Later on in the season and until January, the coverage shifts to the south due to the dependence of the instrument on sunlight. Early on, and until June, the coverage shifts to the north, but the main features of the coverage remain the same as for October 2011, the month displayed in Fig. 2.

The column-averaged dry-air mole fractions of the methane $\left(\mathrm{xCH}_{4}\right)$ product from SCIAMACHY used in this study are provided by an algorithm based on the proxy method developed at SRON in collaboration with JPL (Frankenberg et al., 2005, 2011). The algorithm uses the $1600 \mathrm{~nm}$ band of SCIAMACHY. In this paper, we used version v5.5 of the product. The product provides a columnaverage dry-air mole fraction of $\mathrm{CH}_{4}$ with an a priori profile of $\mathrm{CH}_{4}$ and its corresponding averaging kernel. Both the a priori and the averaging kernel have 12 vertical levels from the lower troposphere to the top of the atmosphere (Fig. 3). As shown by the shape of the averaging kernel, the retrieved $\mathrm{xCH}_{4}$ from SCIAMACHY are more sensitive to the lower troposphere.

The proxy method provides $\mathrm{xCH}_{4}$ proxy based on the ratio between the $\mathrm{CH}_{4}$ number column $\left(\mathrm{vCH}_{4}\right)$ and the $\mathrm{CO}_{2}$ number column $\left(\mathrm{vCO}_{2}\right)$, 


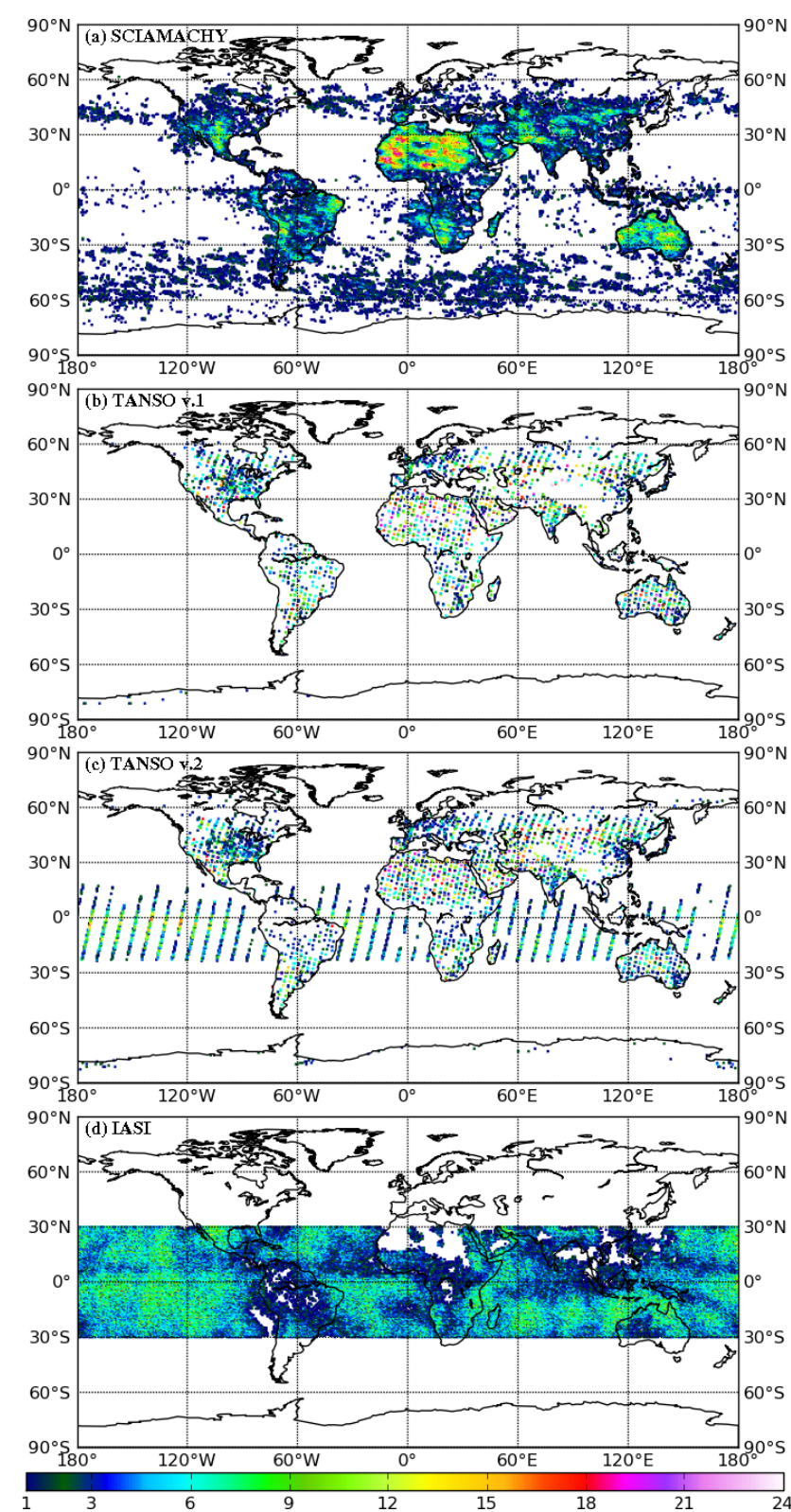

Figure 2. Number of assimilated observations in October 2011, for (a) SCIAMACHY, (b) TANSO v.1, (c) TANSO v.2.0, and (d) IASI. The observations are gridded on a $0.7^{\circ} \times 0.7^{\circ}$ grid.

$\mathrm{xCH}_{4}{ }^{\text {proxy }}=\frac{\mathrm{vCH}_{4}}{\mathrm{vCO}_{2}} \cdot \mathrm{xCO}_{2}{ }^{\text {prior }}$.

The prior column-averaged dry-air mole fraction of $\mathrm{CO}_{2}$ $\left(\mathrm{xCO}_{2}{ }^{\text {prior }}\right)$ is computed from $\mathrm{CO}_{2}$ mole fractions provided by CarbonTracker (carbontracker.noaa.gov). The CarbonTracker $\mathrm{CO}_{2}$ fields are gridded on cells of $1^{\circ} \times 1^{\circ}$ over North America and $3^{\circ} \times 2^{\circ}$ elsewhere. For each SCIAMACHY pixel, the $\mathrm{CO}_{2}$ value in the nearest neighbour cell of the CarbonTracker grid is used to calculate $\mathrm{xCH}_{4}$. At the time of

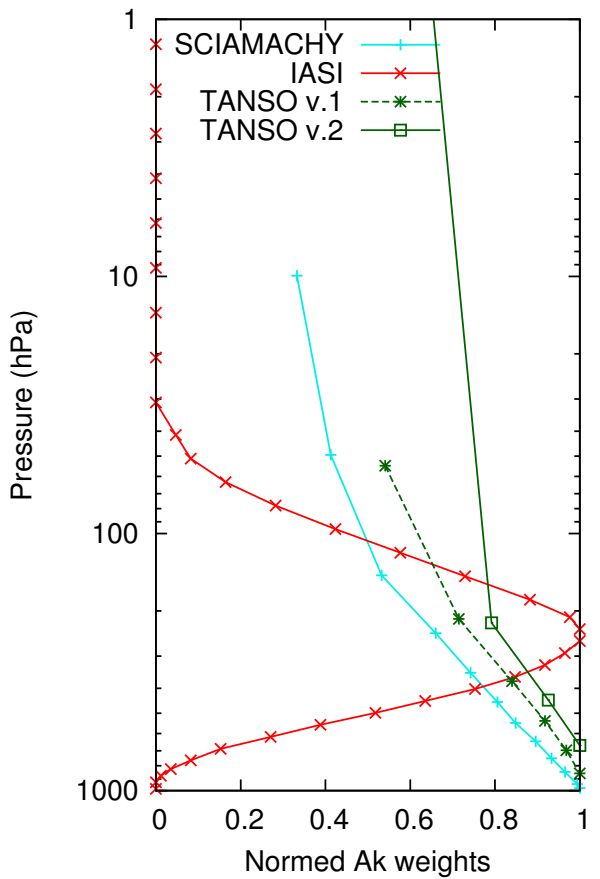

Figure 3. Example of averaging kernels (cyan: SCIAMACHY, dotted green: TANSO v.1 and full green: TANSO v.2.0) and weighting function normalised by the maximum value (red: IASI) of the $\mathrm{CH}_{4}$ products from the different instruments.

writing this paper, CarbonTracker provides $\mathrm{CO}_{2}$ for 2011, but in 2010 , when the $2010 \mathrm{xCH}_{4}$ SCIAMACHY product was produced, the available data set from CarbonTracker was from 2007. Assuming a yearly increase in $\mathrm{CO}_{2}$ of $0.4 \%$, a multiplicative factor of $(1.004)^{3}$ was applied to the 2007 CarbonTracker $\mathrm{CO}_{2}$ fields in order to produce the $2010 \mathrm{xCH}_{4}$ product. When the $2011 \mathrm{xCH}_{4}$ SCIAMACHY product was produced, the 2010 release of CarbonTracker was available, so a multiplicative factor of 1.004 was applied to the 2010 CarbonTracker $\mathrm{CO}_{2}$ fields in order to produce the $2011 \mathrm{xCH}_{4}$ product. The standard deviations of the observation error provided with the data do not vary much in time during the study period. Its average value is $60 \mathrm{ppb}$.

It is well known that SCIAMACHY NIR channels suffered from severe radiation damage (Kleipool et al., 2007; Frankenberg et al., 2011), thereby affecting their performance by increasing the measurement noise error (Gloudemans et al., 2008). This becomes worse towards the end of the mission, which is the period used in this study.

\subsubsection{TANSO}

GOSAT is a joint effort from the Japan Aerospace Exploration Agency (JAXA), the National Institute for Environmental Studies (NIES) and the Japanese Ministry of the Environment (MOE) as part of the Global Change Observation Mission (GCOM) programme of Japan. GOSAT was 
launched on 23 January 2009, into a sun-synchronous orbit at an altitude of $666 \mathrm{~km}$. This implies that the satellite comes back to the same location with a 3-day period.

GOSAT carries the TANSO observing instrument, which consists of a Fourier transform spectrometer (TANSO-FTS) and a cloud and aerosol imager (TANSO-CAI). Two out of the four bands measured by TANSO-FTS are sensitive to $\mathrm{CH}_{4}$, one in the short-wave infrared (SWIR) and one in the thermal infrared (TIR) (for more details see http://www. gosat.nies.go.jp/eng/gosat/page2.htm). Each detector has the same circular field of view of $10.5 \mathrm{~km}$ when projected onto the Earth's surface (at exact nadir), and a swath of $750 \mathrm{~km}$. Compared to SCIAMACHY, which had a continuous coverage across the swath (for clear-sky conditions) and thus 16 observations, TANSO makes only 5 observations across the swath due to the measurement time.

The $\mathrm{xCH}_{4}$ TANSO product used in this study is also provided by SRON using the proxy setup of the RemoTeC algorithm (Butz et al., 2010), a joint development between SRON and KIT. In this paper, we use version v.1 (from November 2010 to September 2011) and version v.2.0 (from October 2011 onward) of the product. These products also consist of column-average dry-air mole fractions of $\mathrm{CH}_{4}$ with an a priori profile and its corresponding averaging kernel. The a priori and the averaging kernel have 6 vertical levels for version v.1 and 4 vertical levels for version v.2.0 (Fig. 3). Note that the TANSO averaging kernels have a similar shape as the SCIAMACHY ones as they both measure in the near infrared. That also makes TANSO sensitive to the lower troposphere. The given values of the observation errors are lower than the ones from SCIAMACHY. Their averaged value is $12.6 \mathrm{ppb}$, which means that the assimilation algorithm will give more confidence to the TANSO data than to the SCIAMACHY ones.

The coverage of both versions of the product is similar over land even when the solar zenith angle limit was changed from $70^{\circ}$ to $75^{\circ}$ (Fig. 2). As for SCIAMACHY, the coverage of the Northern Hemisphere is larger during the summer, reaching $70^{\circ} \mathrm{N}$ or $75^{\circ} \mathrm{N}$ (depending on the version of the product), and smaller during the winter, reaching $50^{\circ} \mathrm{N}$. Contrary to SCIAMACHY, the coverage of the Southern Hemisphere does not vary much with the season. The measurements are mainly located north of $45^{\circ} \mathrm{S}$, with few points over Antarctica. Version v.2.0 of the product provides data over the oceans (sunglint instrument pointing) where no data were retrieved in version v.1. These observations over oceans are located in a tropical band that varies with the season, with more measurements in the Northern Hemisphere during June-July-August (JJA) and more measurements in the Southern Hemisphere during DecemberJanuary-February (DJF). These observations allow one to increase the number of assimilated data per $12 \mathrm{~h}$ assimilation window from about 200 observations (for version v.1) to about 360 observations (for version v.2.0). This nevertheless remains more than 3 times less than the number of assimilated SCIAMACHY observations.

\subsubsection{IASI}

The first Infrared Atmospheric Sounding Interferometer (IASI) developed by the Centre National d'Etudes Spatiales (CNES) in collaboration with the European Organisation for the Exploitation of Meteorological Satellites (EUMETSAT) was launched in October 2006 onboard the European MetOpA platform. IASI is a Fourier transform spectrometer based on a Michelson interferometer coupled to an integrated imaging system that measures infrared radiation emitted from the Earth from 645 to $2760 \mathrm{~cm}^{-1}$, with a spectral resolution of $0.5 \mathrm{~cm}^{-1}$ apodised and a spectral sampling of $0.25 \mathrm{~cm}^{-1}$.

MetOp-A flows in a sun-synchronous polar orbit at an altitude of $817 \mathrm{~km}$. IASI is an across-track scanning system with a scan range of $\pm 48.3^{\circ}$ (symmetric with respect to the nadir direction). A nominal scan line covers 30 scan positions towards the Earth. Each instantaneous field of view has a ground resolution of $12 \mathrm{~km}$ at nadir. This provides about 4000 observations to assimilate per $12 \mathrm{~h}$ window.

The $\mathrm{CH}_{4}$ IASI retrievals used in this study are provided by a non linear inference scheme based on Multilayer Perceptron neural networks (Crevoisier et al., 2009, 2013). This method relies on the simultaneous use of synchronised observations from IASI and the Advanced Microwave Sounding Unit (AMSU) to disentangle $\mathrm{CH}_{4}$ from atmospheric temperature in the IASI radiances. IASI provides sub-column of $\mathrm{CH}_{4}$ in the middle to upper troposphere, with associated weighting functions having their maximum at $250 \mathrm{hPa}$ (Fig. 3). In this study we restricted the data to a large tropical belt $\left(30^{\circ} \mathrm{N}-30^{\circ} \mathrm{S}\right)$ where higher-quality data are expected compared to higher latitudes because of the low variability of the temperature profiles, which facilitates the decorrelation between $\mathrm{CH}_{4}$ and temperature signals. In that region, the given mean observation error is $37 \mathrm{ppb}$. It is slightly higher during spring (2011 and 2012) and slightly lower during the summer 2011.

Compared to SCIAMACHY, which provides dense information mainly over land, and compared to TANSO, which provides sparse information, IASI provides a very dense observation pattern over both land and ocean, for clear-sky conditions only. For example, in October, each grid point is observed on average 11 times (less than for SCIAMACHY and TANSO), but most of the grid points are observed (Fig. 2). Only North Africa and Asia have some gaps because of specific surface conditions over the Sahara and the persistence of cloudy conditions, especially during the monsoon. One can note that the observational coverage over the oceans is slightly better than over the land. 


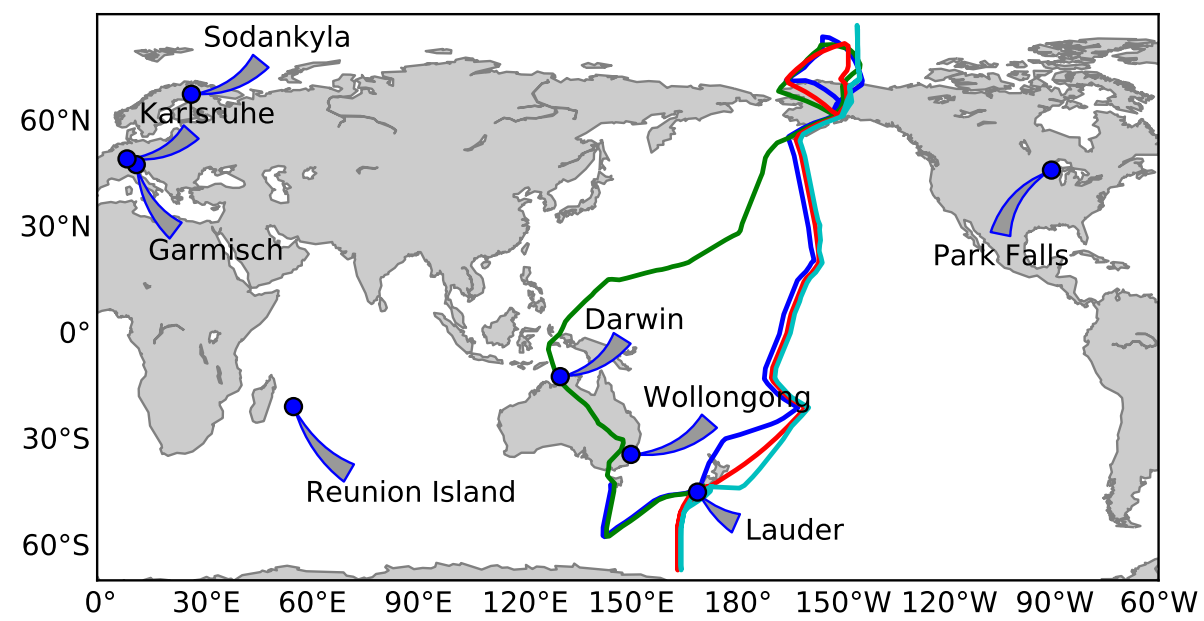

Figure 4. Location of a few TCCON stations used in this paper (blue points) and trajectories of the 2011 HIPPO campaigns. The campaign periods are respectively 16-29 June (blue), 28 June-11 July (green), 19-30 August (red), and 29 August-9 September (cyan). Note that for the plot, some trajectories are shifted one or two degrees east or west in order to avoid superposition between them.

\subsection{Set-up of experiments}

We decided to start the study period on 1 November 2010 in order to have more than one year of SCIAMACHY data to assimilate before April 2012, the month the contact with Envisat was lost. When we started the study, the MACC-II DM system had been running since June 2009, assimilating SCIAMACHY $\mathrm{CH}_{4}$ products. This run was the reference at that time and we decided to use it to build the initial conditions for the SCIA experiment. We thus extracted the meteorological parameters and the methane concentration from the DM analysis for 1 November 2010 and used them as initial conditions. The SCIA experiment is then a clone of the DM but at a different resolution. The two other analysis experiments use the same initial condition, so we can assess the impact of the change in the observing system. The FREE run also uses this initial condition in order to evaluate the impact of the assimilation better.

The study period runs from the beginning of November 2010 to the end of April 2012 (18 months), when SCIAMACHY stopped producing data (Fig. 1). Occasionally we split the period studied into seasons to interpret the results. Note that the first completed season studied, i.e. December 2010, January and February 2011 (DJF 2010/2011), starts one month after the beginning of the study period. This first month can thus be regarded as a spin-up period.

\subsection{Evaluation data}

The non-satellite $\mathrm{CH}_{4}$ data are mainly measurements of the near-surface concentrations. For example, in situ measurements are provided by the National Oceanic and Atmospheric Administration (NOAA) network (http://www.esrl. noaa.gov/gmd/) and the pre-operational Integrated Carbon Observation System (ICOS) network (https://icos-atc-demo. lsce.ipsl.fr). As the assimilated data are columns, they do not constrain the surface level well in the analysis; therefore, we decided to carry out the validation of the analyses using profiles and column measurements. We chose some campaigns from the HIAPER Pole-to-Pole Observations (HIPPO, Wofsy et al., 2011, http://hippo.ornl.gov/) and the measurements from the Total Carbon Column Observing Network (TCCON, Wunch et al., 2011, https://tccon-wiki. caltech.edu). The flight data cover 3 months of the studied period with a good vertical resolution, while the groundbased data cover the whole period but provide only the vertically integrated information in a few places over the Globe.

During the period under study, four HIPPO campaigns took place between 16 June and 9 September 2011. Three of them have a similar trajectory for the flights over the Pacific Ocean (Fig. 4). The second campaign from 28 June to 11 July 2011 has its flights more towards the west and crossing Australia and Indonesia. In this paper, the $10 \mathrm{~s}$ merged methane product was used (Wofsy et al., 2012).

At the time of writing, twenty-one stations of the TCCON network have reported data for the period we are interested in. We chose to compute global statistics using all these stations and additionally differentiating them by regions and by period. Most of the used data are located north of $20^{\circ} \mathrm{N}$ (about $70 \%$ ). The data collected over the tropical region represent $8 \%$ and only $4 \%$ for the period before October 2011. Moreover, eight stations were chosen to present time series (Fig. 4). Some stations were retained because they provided the most continuous data set (e.g. Park Falls). We also kept the stations located in the tropical area in order to assess the impact of the assimilation of the IASI data. The two stations located at the two highest latitudes (north and south) were also selected (e.g. Lauder and Sodankyla). 


\section{Results}

In the following, we present the results of the FREE experiment and the three assimilation experiments by comparing the latter to the free run.

\subsection{Free run}

Unlike for a CTM, the FREE experiment consists here of forecasting both the $\mathrm{CH}_{4}$ mole fraction and the meteorological parameters. The meteorological parameters are free to evolve without any constraint during the forecast. In order to have more accurate meteorological parameters, we replaced them every $12 \mathrm{~h}$ with the ones from one of our assimilation experiment (all our analyses presented in this paper having the same meteorological parameters). These analysed meteorological parameters result from the assimilation of all the operational meteorological data in IFS.

Methane is free to evolve without any constraint by observations in the FREE experiment. Its evolution is subject to the transport, the fluxes and the chemical loss rates. The fluxes are the largest source of uncertainty for $\mathrm{CH}_{4}$ in this experiment and they are also the main driver of its evolution. Even if there is no constraint on the fluxes or on the $\mathrm{CH}_{4}$ mole fraction, the forecast $\mathrm{CH}_{4}$ is realistic enough to provide us with the reference to assess the effect of the assimilation of $\mathrm{CH}_{4}$ data. This simulation represents the main features of atmospheric $\mathrm{CH}_{4}$ like the north-south gradient as well as the seasonal variability of the Northern Hemisphere (Fig. 5).

One can notice an increase in the global trend of the methane total column. This is due to the modelled $\mathrm{CH}_{4}$ growth, i.e. a net positive balance of the sources and the sinks.

\subsection{SCIAMACHY analysis}

Due to the fact that SCIAMACHY measures reflected solar light, SCIAMACHY can only provide daytime measurements. This leads to gaps in the global coverage during local winter periods (Fig. 6a). To assess how the analysis deals with these gaps, we computed the seasonal averages of the analysis increment as a total column (difference between $\mathrm{xCH}_{4}$ computed from the analysis and $\mathrm{xCH}_{4}$ computed from the background state, Fig. 7a). An averaged increment is representative of a systematic mismatch between the background state (computed by a $12 \mathrm{~h}$ forecast from the previous analysis) and the observations. We do not discuss here the values of the averaged increment as the biases are not the focus of this paper. We use this diagnostic to present where the observations add information through the analysis.

The structure of the averaged increment shows that the analysis of SCIAMACHY brings information mainly over land in the tropical region and at mid-latitudes but not over the ocean. Depending on the season, the analysis brings information at high latitudes (Northern Hemisphere in JJA and
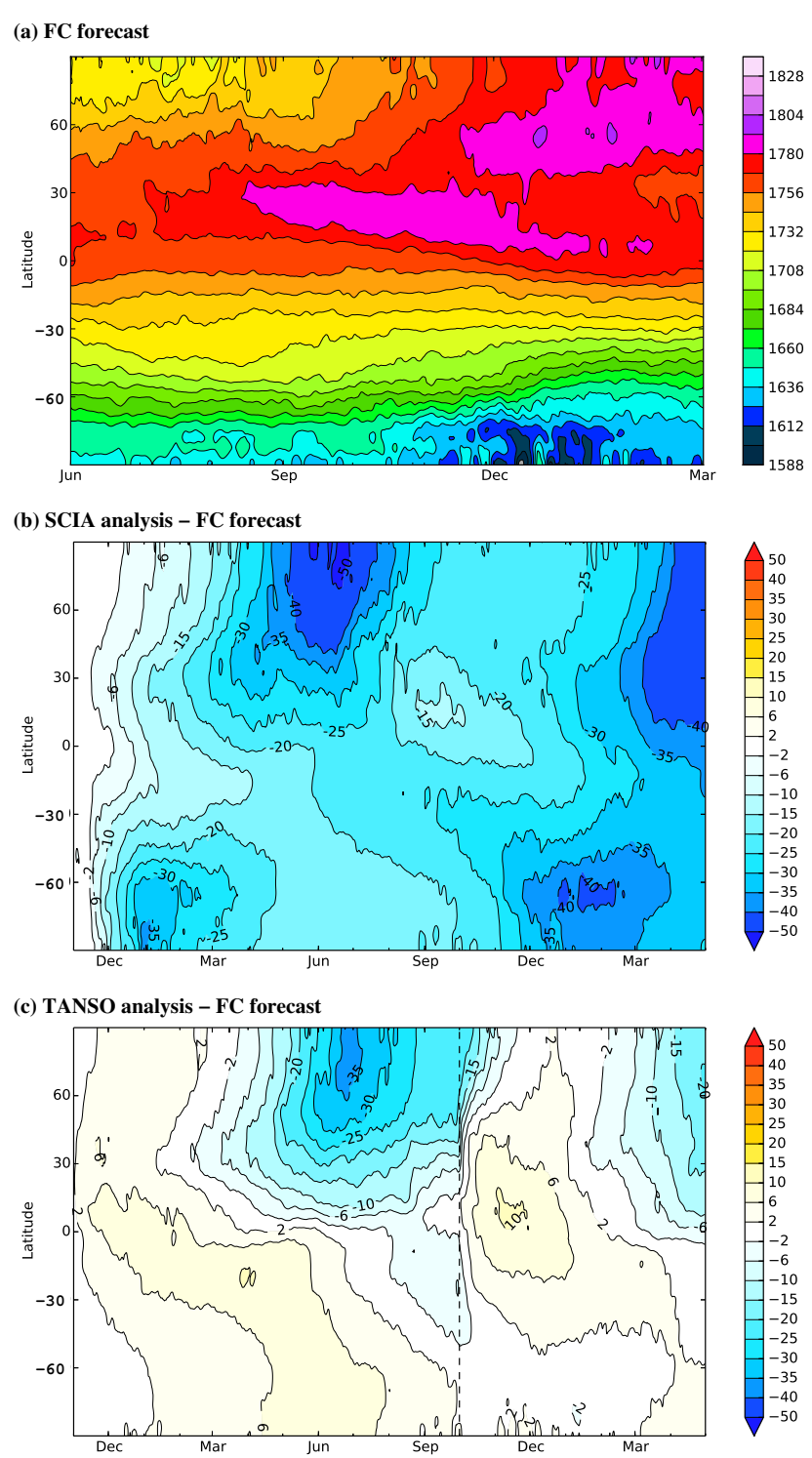

(d) IASI+TANSO analysis - TANSO analysis

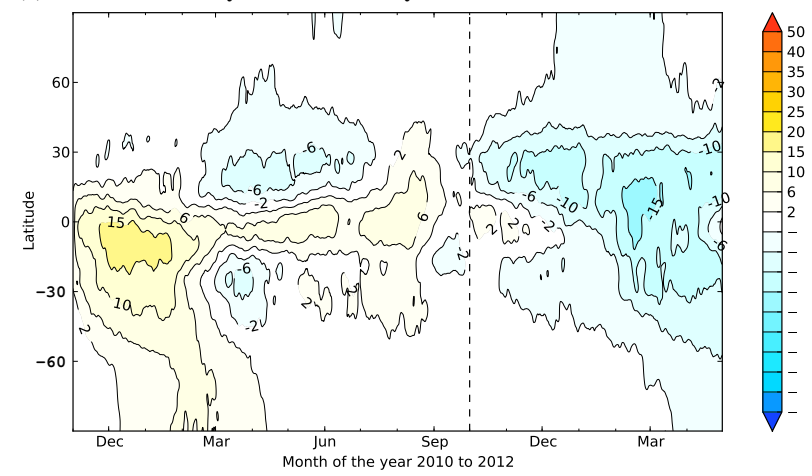

Figure 5. Time series of $\mathrm{xCH}_{4}$ zonal mean (in ppb). From top to bottom: (a) FREE free run, (b) SCIA analysis - FREE, (c) TANSO analysis - FREE, (d) IASI+TANSO analysis - FREE. The vertical dotted line corresponds to the date when version v.2.0 of the data replaces version $\mathrm{v} .1$. 

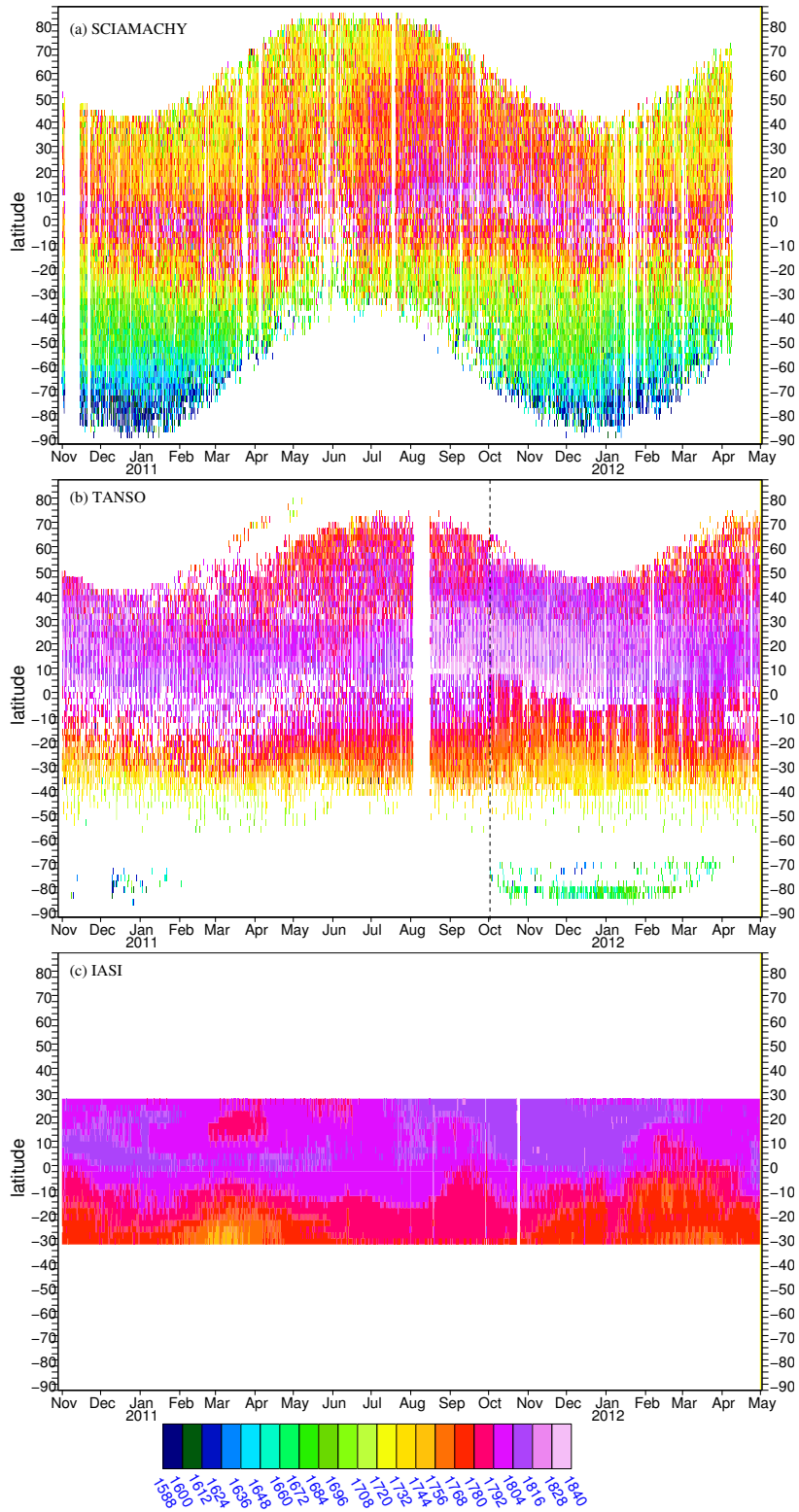

Figure 6. Time series of $\mathrm{xCH}_{4}$ zonal mean (in ppb) from (a) SCIAMACHY, (b) TANSO and (c) IASI products (from top to bottom).

Southern Hemisphere in DJF) over ocean and land. The direct impact of the assimilation of the SCIAMACHY product should therefore be found over the tropics to the midlatitudes and at higher latitudes of each hemisphere during summertime. When the $\mathrm{CH}_{4}$ total columns from the SCIA experiment are compared to the ones from the FREE experiment, the main difference is at high latitudes of the Northern Hemisphere in June (Fig. 5b). Total columns from the SCIA experiment are locally more than $50 \mathrm{ppb}$ lower than those from the FREE experiment. This difference corresponds to a lower $\mathrm{CH}_{4}$ mole fraction in the range from the surface to the lower stratosphere, up to $50 \mathrm{hPa}$ in the analysis. (Fig. 8, left panels). The difference is largest in the troposphere and particularly at levels close to the surface.

At high latitudes in the Southern Hemisphere, the main differences are observed during DJF, which corresponds to the local summer. There, the SCIA experiment has less $\mathrm{CH}_{4}$ than for the FREE experiment from the surface up to 100 or $50 \mathrm{hPa}$ (depending on the year). The largest differences of more than $30 \mathrm{ppb}$ are found from the near surface to the upper troposphere. This corresponds to differences of about 20 to $30 \mathrm{ppb}$ in terms of averaged total columns. One can notice that during the wintertime of each hemisphere, there is an indirect impact of SCIAMACHY as $\mathrm{xCH}_{4}$ remains lower in the SCIA experiment compared to the FREE experiment. This is due to both the transport that spreads the observation information in space and time, and the model adjustment to its equilibrium state.

Over the tropical region, the analysis also has lower methane concentrations than the FREE experiment. The differences are higher in March-April-May (MAM) and JJA 2011, with values between 15 and 25 ppb, and in MAM 2012 with values between 30 and $40 \mathrm{ppb}$. The result of these seasonal differences as well as the differences at the highest latitudes is a modification of the north-south gradient and the seasonal cycle in the SCIA experiment compared to the FREE experiment. In the SCIA experiment the gradient is steeper in DJF and flatter in JJA, and the seasonal cycle is more pronounced.

\subsection{TANSO analysis}

The TANSO data are available during most of the period under study, apart for a few days in August 2011 (Fig. 6b). The Southern Hemisphere is less well sampled as there is little or no coverage of the oceans and the coverage mostly stops for latitudes south of $45^{\circ} \mathrm{S}$. SCIAMACHY thus has an added value in this region south of $45^{\circ} \mathrm{S}$, as its data impact the analysis during the local summer period as seen previously (Sect. 3.2). The averaged increments of the TANSO experiment show however that the TANSO data have an influence over Antarctica similar to the SCIAMACHY data (but to a lesser extent) in DJF 2011/2012 (Fig. 7). They also have an influence over oceans at southern mid-latitudes, while the SCIAMACHY data have an influence further south. In JJA, where both data sets are available, their region of influence is similar. At middle and high northern latitudes, SCIAMACHY data additionally have an influence over oceans. In summary, the averaged increments show that even if the TANSO data are sparser than the SCIAMACHY data, their region of influence is similar over the tropics and midlatitudes.

The assimilation of the TANSO data has less impact on the analysis than the assimilation of the SCIAMACHY data when compared to the FREE experiment (Fig. 5c). The difference between the $\mathrm{CH}_{4}$ column from the TANSO experiment and from the FREE experiment is mostly less than 
(a) SCIA JJA 2011

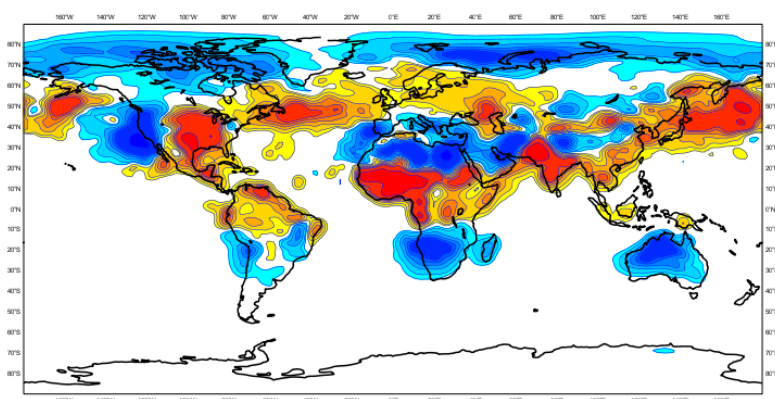

(c) TANSO JJA 2011

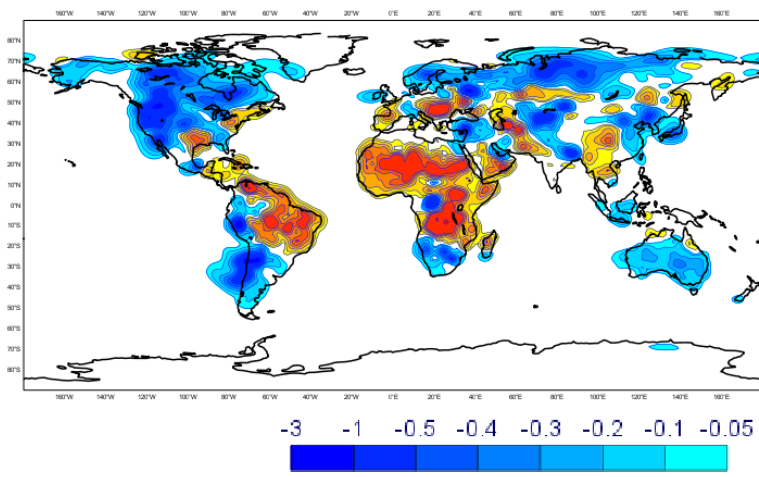

(b) SCIA DJF 2012

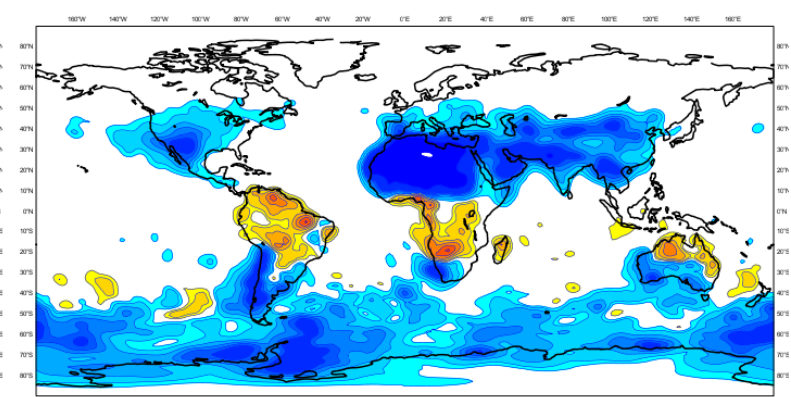

(d) TANSO DJF 2012

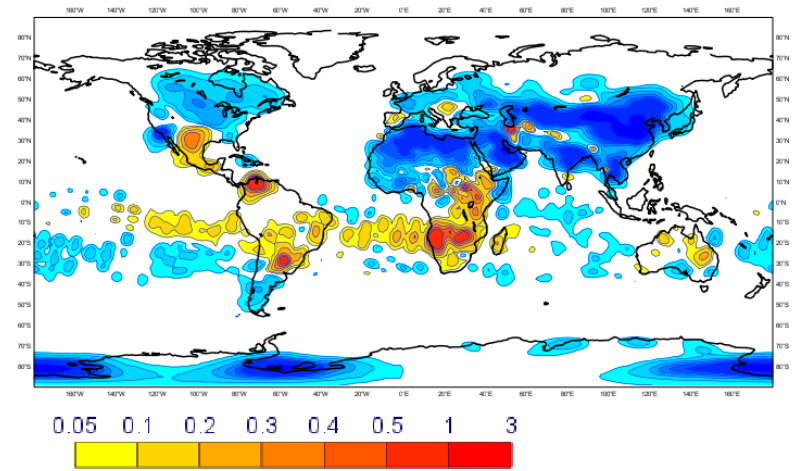

Figure 7. Seasonal average of the increment in terms of $\mathrm{CH}_{4}$ total column, for JJA 2011 (left) and DJF 2011/2012 (right) in ppb per $12 \mathrm{~h}$. From top to bottom: SCIA analysis and TANSO analysis.

$10 \mathrm{ppb}$, but here the analysis has higher $\mathrm{CH}_{4}$ values than the FREE experiment. This is the main characteristic of this experiment compared to the SCIA one. The exception is for the summer period at northern high latitudes. As for the SCIA analysis, the TANSO analysis reduces the lower atmospheric $\mathrm{CH}_{4}$ compared to the FREE experiment, but whereas the reduction exceeds $50 \mathrm{ppb}$ for the SCIA experiment, it is here less than $40 \mathrm{ppb}$. The TANSO measurements are limited to $82^{\circ} \mathrm{N}$, but due to the transport and the background error correlation, the information is spread to higher latitudes. This compensates for the lack of TANSO data at the high latitudes.

The TANSO data influence the vertical distribution of the analysed $\mathrm{CH}_{4}$ compared to the vertical distribution from the FREE experiment mainly over the northern extra-tropical region from MAM to September-October-November (SON, Fig. 8, central panels), as for the total columns. The differences reach their maximum in JJA with a $\mathrm{CH}_{4}$ mole fraction lower for the analysis (compared to FREE). The maximum value of the difference is more than $30 \mathrm{ppb}$ and it is found from the surface to $500 \mathrm{hPa}$. The TANSO data constrain the whole troposphere, as is the case for SCIAMACHY.

Note that the difference between the TANSO experiment and the FREE experiment in the stratosphere is similar to the one between the SCIA experiment and the FREE experiment. This is likely due to the transport of higher $\mathrm{CH}_{4}$ concentrations from the tropics to high latitudes by the meridional cir- culation in the stratosphere. The $\mathrm{CH}_{4}$ concentration is higher in the stratosphere over the tropics for the analysis experiments compared to the FREE experiment due to systematic positive increments in regions of deep convection (Fig. 7a and c).

\subsection{TANSO and IASI analysis}

When the IASI data are added to the TANSO data in the analysis, their effect is evaluated by comparing the resulting analysis with the TANSO analysis (Fig. 5d). The comparison emphasises the impact of the change in the version of the assimilated TANSO data in October 2011. The IASI+TANSO experiment has between 5 and $15 \mathrm{ppb}$ less methane in the total column after October 2011 than for the TANSO experiment. Before this date, the difference is mainly between -5 and 5 ppb, except for DJF 2010/2011 when the total column values from the IASI+TANSO experiment are $15 \mathrm{ppb}$ higher. The difference between the two experiments is mainly located in the tropical and middle latitude regions south of $30^{\circ} \mathrm{N}$ and north of $30^{\circ} \mathrm{S}$ where the IASI data are provided. The transport and the background error correlation, however, spread the information to the higher latitudes, but there the difference is never much more than $2 \mathrm{ppb}$.

The weighting function of the IASI product peaks at about $250 \mathrm{hPa}$. It reaches half of its maximum respectively at $100 \mathrm{hPa}$ and $500 \mathrm{hPa}$. One can expect to see the influence of the assimilation of the IASI data mainly in this vertical 


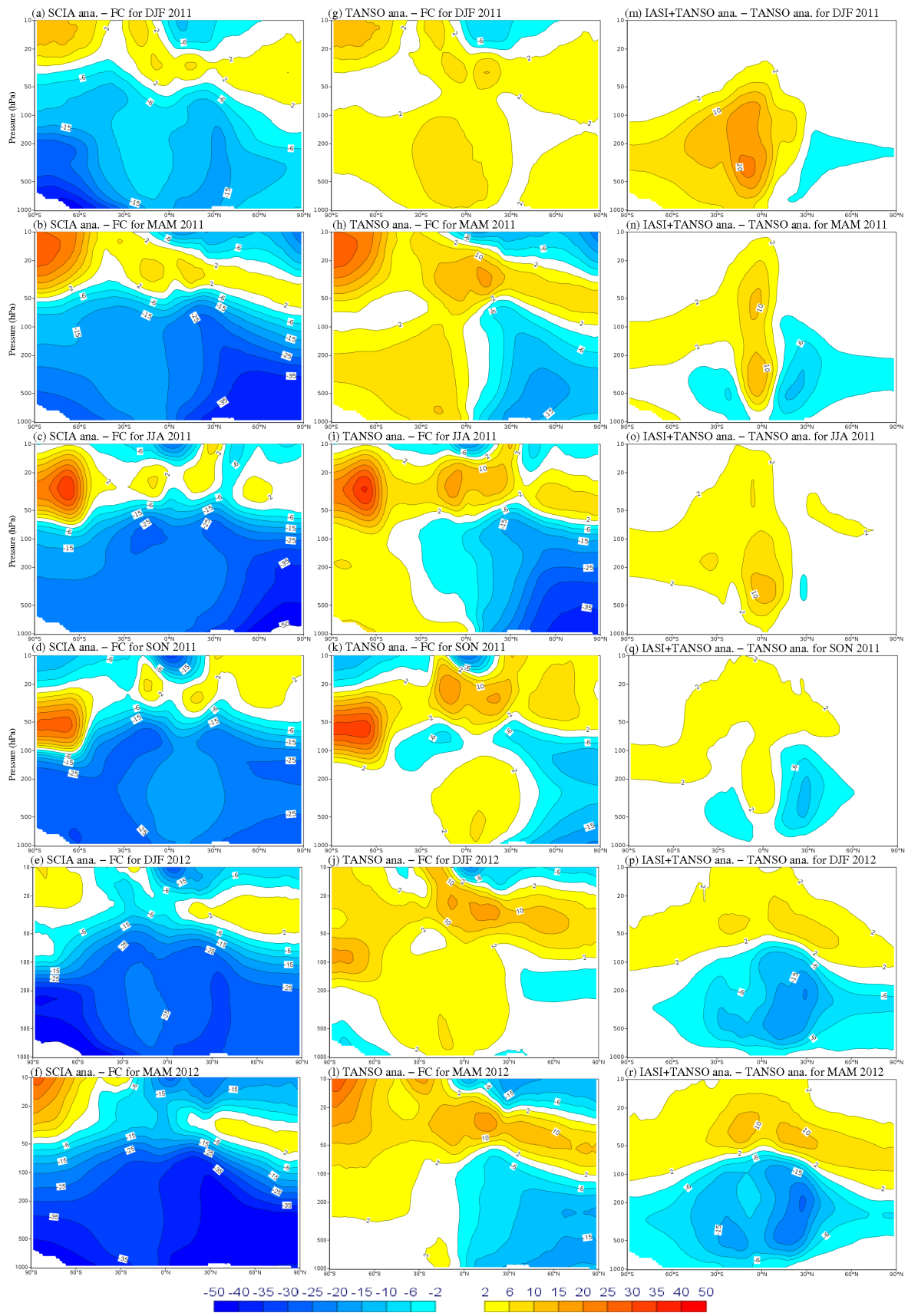

Figure 8. Seasonal and zonal mean difference between the $\mathrm{CH}_{4}$ mole fraction (in ppb): from the SCIA experiment and the FREE free run (left); from the TANSO experiment and the FREE free run (middle); from the IASI+TANSO experiment and the TANSO experiment (right), The seasonal means are from the top to the bottom row: DJF 2010/2011, MAM 20111, JJA 2011, SON 2011, DJF 2011/2012 and MAM 2012.

region between 100 and $500 \mathrm{hPa}$, but looking at the differences between the zonal and seasonal averages from the IASI+TANSO experiment and from the TANSO experiment, the influence is observable from the surface up to $10 \mathrm{hPa}$ (Fig. 8, right panels). This could be explained by the vertical transport as well as by the vertical correlation in the back- ground error statistics or the interaction with the TANSO data.

From December 2010 to April 2011, the IASI data constrain the analysis so that it has higher values of methane concentration in the middle troposphere over the tropics compared to the TANSO analysis. For the extra-tropical regions, the impact is more dependent on the season. The 
Table 1. Average difference (in ppb) between the free run or the analyses and the HIPPO data. The average is computed for the four campaigns and for data below $300 \mathrm{hPa}$ in height. It is also split into regions: Northern Hemisphere above $20^{\circ} \mathrm{N}(\mathrm{NH})$; tropics between $20^{\circ} \mathrm{S}$ and $20^{\circ} \mathrm{N}$ (Trop); Southern Hemisphere below $20^{\circ} \mathrm{S}(\mathrm{SH})$.

\begin{tabular}{lrrrr}
\hline & NH & Trop & SH & Global \\
\hline FREE & 2.68 & -6.43 & -12.55 & -4.98 \\
SCIA & -36.38 & -31.41 & -34.45 & -34.64 \\
TANSO & -27.55 & -13.98 & -8.80 & -17.65 \\
TANSO+IASI & -29.68 & -12.56 & -7.35 & -17.69 \\
\hline
\end{tabular}

IASI analysis tends nevertheless to decrease $\mathrm{CH}_{4}$ in the middle troposphere and to increase it in the lower stratosphere. For the last two seasons (DJF 2011/2012 and MAM 2012) the shape of the difference between the two experiments (IASI+TANSO and TANSO) differs substantially from the previous seasons. The previously described decrease in terms of $\mathrm{xCH}_{4}$ during these two seasons is associated with a decrease in $\mathrm{CH}_{4}$ by more than $15 \mathrm{ppb}$ from the surface to $100 \mathrm{hPa}$ in the tropics and at the same time an increase (less than $10 \mathrm{ppb}$ ) above $100 \mathrm{hPa}$. Due to the transport, these differences spread to the extra-tropical regions.

\subsection{Comparison with independent measurements}

The three $\mathrm{CH}_{4}$ analyses showed their own features in terms of $\mathrm{CH}_{4}$ spatial and temporal distribution when compared to the simulation without data assimilation. To further document the features of each analysis, they are compared to evaluation data, i.e. data that have not been directly included in the assimilation process. One can notice that these evaluation data are not always fully independent as, for example, satellite products are bias-corrected using the measurements from the TCCON network.

\subsubsection{Comparison with HIPPO}

For each $\mathrm{CH}_{4}$ concentration measured during the campaigns, we computed the model equivalent for each of our four experiments. The top panel of Fig. 9 presents the measurements for the four campaigns as a function of latitude and altitude (in pressure units), and for each experiment, we present the same figure but for the difference between the model and the measurement (Fig. 9, rows 2 to 5). We removed for each experiment the average difference between the model and the measurements to compare the spatial gradient between the experiments better. These differences are spatial and temporal averages over the four campaigns and are detailed in Table 1 . We also computed the average differences for three spatial regions: the Northern Hemisphere north of $20^{\circ} \mathrm{N}$, the tropics between $20^{\circ} \mathrm{S}$ and $20^{\circ} \mathrm{N}$ and the Southern Hemisphere south of $20^{\circ} \mathrm{S}$.
From the four campaigns, we can identify in the HIPPO data the north-south gradient in the $\mathrm{CH}_{4}$ distribution with lower values in the Southern Hemisphere (Fig. 9a). We can also clearly assess the vertical gradient when the flight crosses the tropopause at around $200 \mathrm{hPa}$ at high latitudes.

The FREE experiment represents the north-south gradient reasonably well for the two last campaigns (Fig. 9b), but it fails to represent correctly the gradient for the two first campaigns with an underestimation over the Southern Hemisphere and an overestimation over the Northern Hemisphere. On average for the campaigns, the underestimation over the Southern Hemisphere is around $13 \mathrm{ppb}$ (Table 1). The underestimation is lower in the tropics with a value of $6 \mathrm{ppb}$, whereas the experiment overestimates $\mathrm{CH}_{4}$ by 3 ppb over the Northern Hemisphere. One can notice from Fig. 9b than the difference between the experiment and the HIPPO data over the Northern Hemisphere is positive for the first two campaigns and negative for the two last ones. This is likely due to a seasonal bias in the model.

As shown in the previous section, the SCIA analysis reduces the north-south gradient during the summer. This leads to a similar inter-hemispheric gradient to that in the HIPPO data (Fig. 9c). The SCIA experiment has a better simulated gradient than the FREE experiment, but overall the analysis underestimates $\mathrm{CH}_{4}$ by about $35 \mathrm{ppb}$ on average (Table 1). This indicates the presence of a bias in the SCIAMACHY product. The average differences between the SCIA experiment and the HIPPO data are similar in the Northern Hemisphere and the Southern Hemisphere, and slightly lower in the tropics. This is consistent with the weak dependence of the bias with the latitude found in the work of Bergamaschi et al. (2009) during the summer months.

We already mentioned the change in the north-south gradient in the TANSO experiment due to a reduction in the tropospheric $\mathrm{CH}_{4}$ in the Northern Hemisphere (Sect. 3.3). When compared to the HIPPO data this reduction appears to be slightly too large (Fig. 9d). The Northern Hemisphere overestimation in the FREE experiment $(3 \mathrm{ppb})$ is replaced with a larger underestimation of $28 \mathrm{ppb}$ in the analysis (Table 1). In the Southern Hemisphere, the impact of the assimilation of the TANSO data is mainly positive (from an underestimation of $13 \mathrm{ppb}$ for the FREE experiment to an underestimation of $9 \mathrm{ppb}$ for the analysis) even at high latitudes where there is no data to constrain the model. This suggests a latitude-dependent bias in version v. 1 of the TANSO product. Figure $9 \mathrm{~d}$ also suggests a seasonal variation of the bias. The differences are indeed larger during the end of the summer (last two campaigns) in the Northern Hemisphere.

When comparing the difference between the IASI+TANSO analysis and the HIPPO data, with the difference between the TANSO analysis and the HIPPO data, we see the impact of the IASI data on the analysis. Globally the IASI+TANSO experiment is similar to the TANSO experiment (Table 1). In the tropics and in the Southern Hemisphere, the difference compared to the 

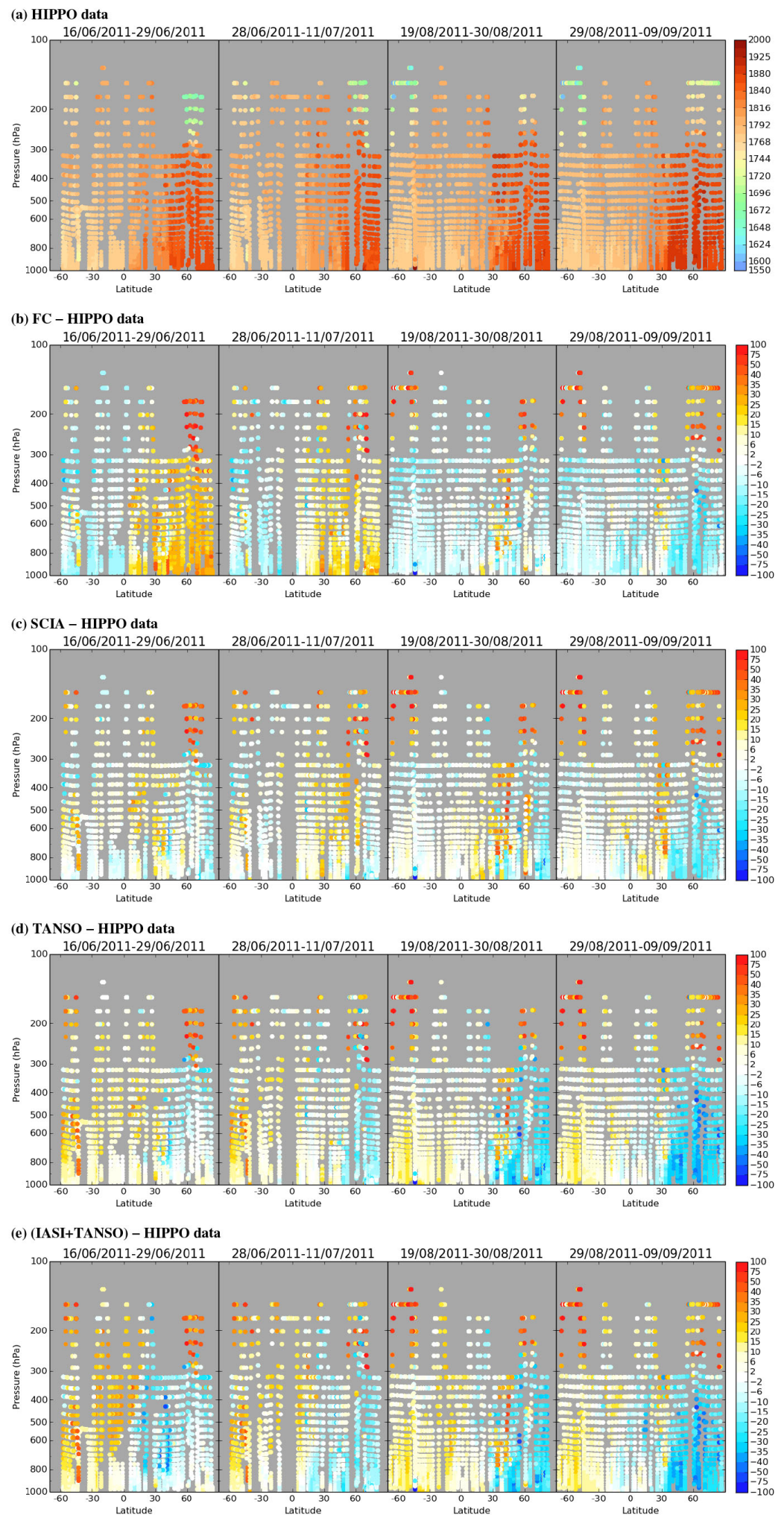

Figure 9. Top row (a): HIPPO $\mathrm{CH}_{4}$ data (latitude vs. pressure, in ppb) for the four campaigns (from the leftmost panel for the first campaign to the rightmost panel for the last campaign). The beginning and end dates of each campaign are detailed on top of each panel. From rows 2 to 5: difference between the experiments and the HIPPO data (in ppb): (b) FREE minus HIPPO, (c) SCIA analysis minus HIPPO, (d) TANSO (v.1) analysis minus HIPPO and (e) TANSO+IASI analysis minus HIPPO. A global bias has been removed from the FREE run and from each analysis (see Table 1). The grey shade means there is no observation. 
Table 2. Same as Table 1 but for the standard deviation.

\begin{tabular}{lrrrr}
\hline & NH & Trop & SH & Global \\
\hline FREE & 16.139 & 9.833 & 7.806 & 14.071 \\
SCIA & 15.504 & 7.792 & 8.049 & 11.850 \\
TANSO & 15.610 & 7.616 & 8.553 & 14.647 \\
TANSO+IASI & 15.466 & 12.232 & 8.941 & 16.319 \\
\hline
\end{tabular}

HIPPO data is nevertheless reduced by about $1.5 \mathrm{ppb}$. In contrast, the difference increased by about $2 \mathrm{ppb}$ in the Northern Hemisphere. In terms of vertical distribution, the difference between the experiments is located mainly above $700 \mathrm{hPa}$ (Fig. 9e).

In order to have another picture of how well the experiments are able to represent the $\mathrm{CH}_{4}$ features as measured during the HIPPO campaigns, we computed the standard deviation of the difference between the measurements and the model equivalent (Table 2). The standard deviation quantifies the random component of the difference. In the following, we will refer to it as the error.

The FREE experiment presents a global error of about $14 \mathrm{ppb}$ which mainly comes from the Northern Hemisphere, the error being respectively $10 \mathrm{ppb}$ and $8 \mathrm{ppb}$ in the tropics and in the Southern Hemisphere. The SCIA experiment has a global lower error (less than $12 \mathrm{ppb}$ ), meaning that the assimilation system correctly uses the information content of the SCIAMACHY data. The error has a different regional distribution compared to the FREE experiment, being lower over the Northern Hemisphere and the tropics but slightly higher in the Southern Hemisphere. The TANSO experiment has a similar error as the error of the SCIA experiment in the Northern Hemisphere, a slightly lower error in the tropics, but a higher error in the Southern Hemisphere. This means that the output of the analysis in this region should be used with caution. Even if the assimilation of the IASI data allows one to reduce the difference compared to the HIPPO measurements, it increases the error in the tropics with a value of $12 \mathrm{ppb}$ for the error of the IASI+TANSO experiment when the FREE experiment has an error of $10 \mathrm{ppb}$ there. Adding the high-density IASI data in the system thus results in an increase in the variability of the tropospheric methane in the analysis.

We saw in Sect. 3.4 that the impact of the IASI data in the vertical distribution of $\mathrm{CH}_{4}$ changed when the data are combined with version v.1 or version v.2.0 of the TANSO data (left column of Fig. 8). Unfortunately we do not have other profile measurements for the second period to document if the IASI+TANSO experiment presents better profiles with version v.2.0 of the TANSO data.

\subsubsection{Comparison with TCCON}

For each TCCON measurement we computed the model equivalent using the TCCON a priori profiles and averag-
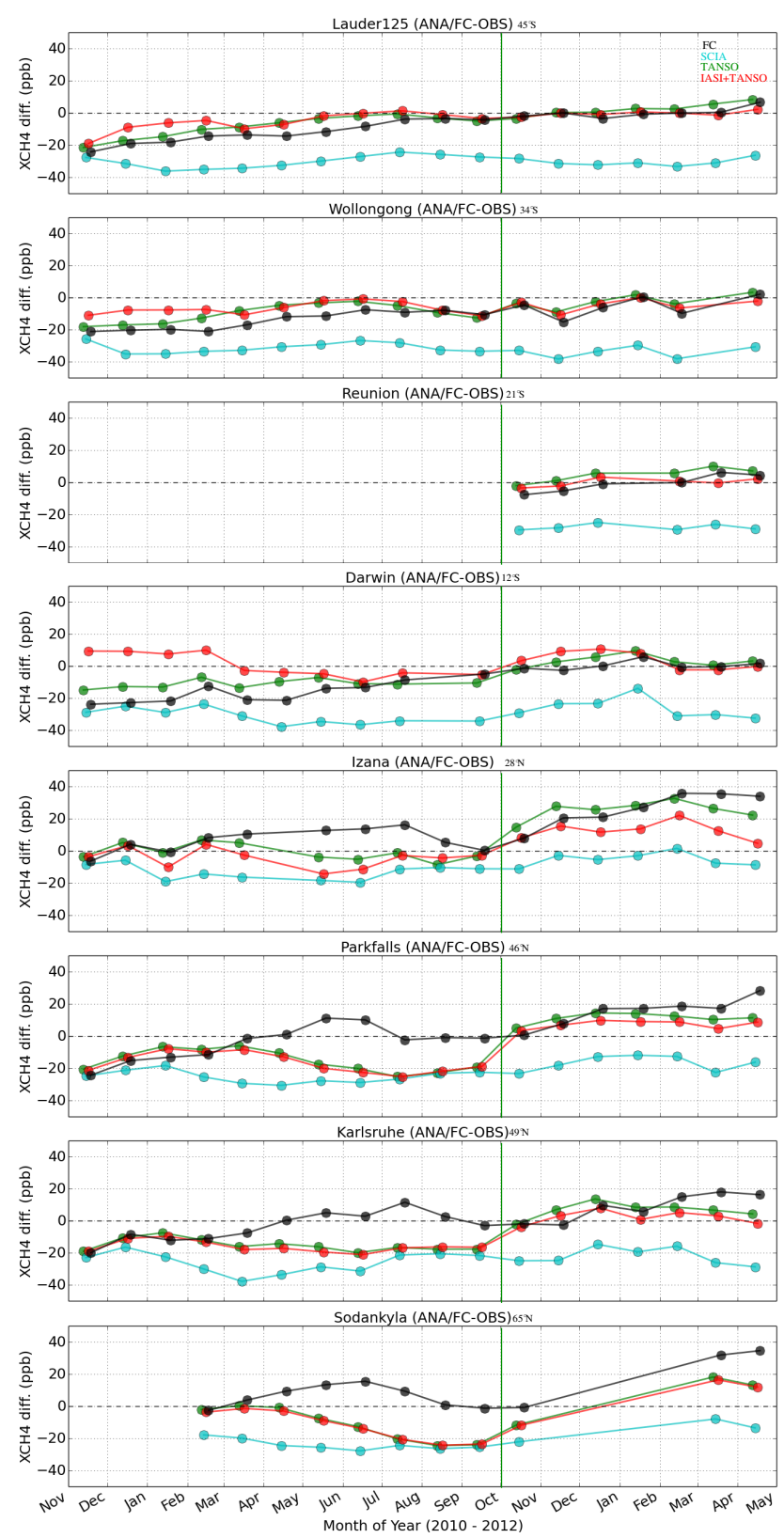

Figure 10. Time series of the monthly differences (in ppb) between $\mathrm{xCH}_{4}$ measurements from the TCCON network and $\mathrm{xCH}_{4}$ from the free experiment (black) and from the analyses (cyan: SCIA, green: TANSO, red: TANSO+IASI). The stations are ordered from the top to the bottom panel by their latitude, from south to north: Lauder, Wollongong, Reunion, Darwin, Park Falls, Garmisch, Karlsruhe, Sodankyla.

ing kernel. To summarise the behaviour of each experiment compared to the TCCON measurements, we then computed the monthly averaged differences between the model and the measurements and the monthly standard deviation of the differences. Figure 10 presents the time series of the monthly differences for several stations. 

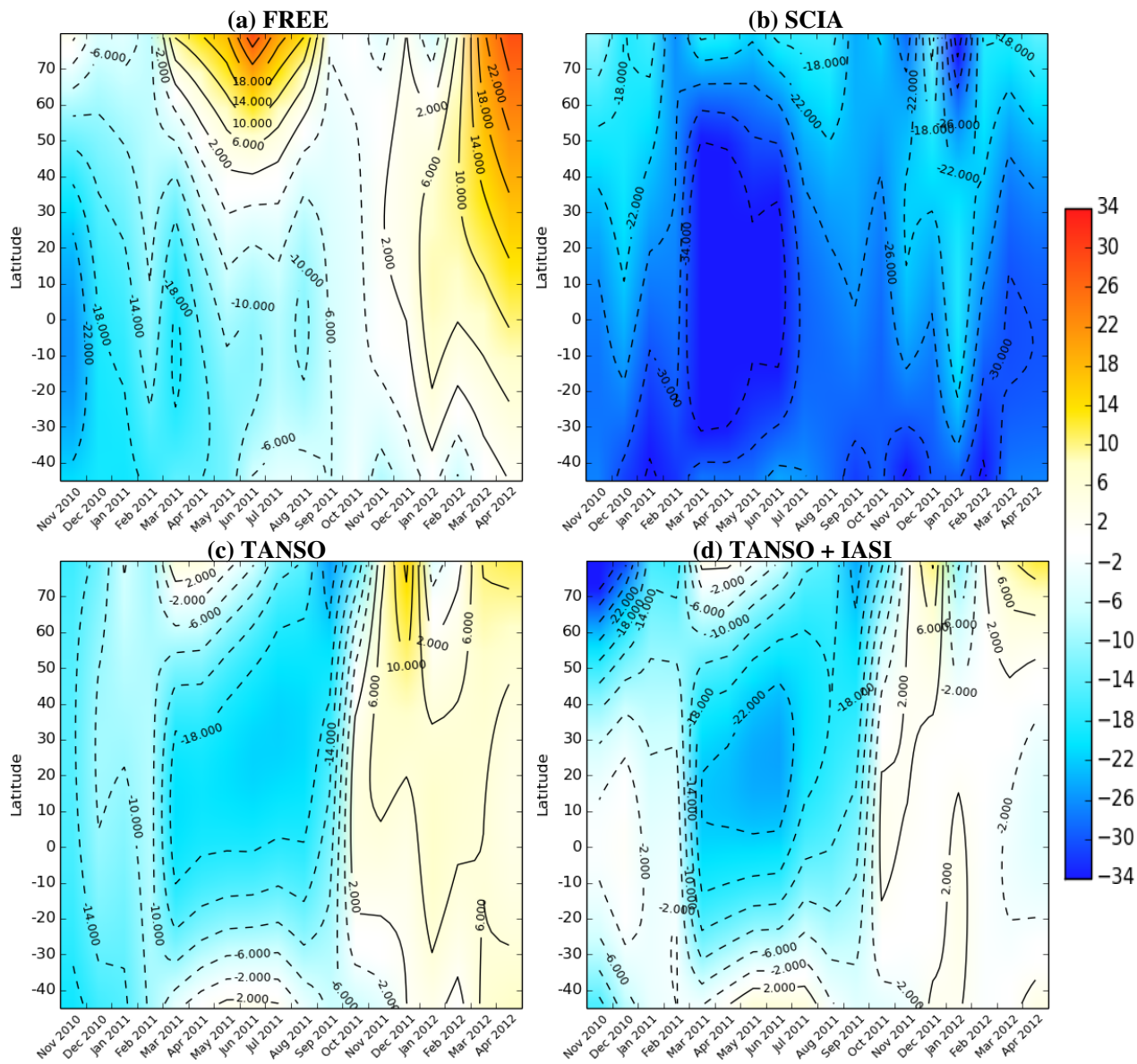

Figure 11. Time series of the monthly average smooth $\mathrm{xCH}_{4}$ difference (in ppb) between the experiments and the measurements from the TCCON network: (a) FREE, (b) SCIA, (c) TANSO and (d) TANSO + IASI experiments.

Following Bergamaschi et al. (2009), we computed the best fit of the monthly differences with a quadratic function of latitude. Figure 11 presents the time series of the monthly quadratic functions. This figure is truncated to the latitude range from $45^{\circ} \mathrm{S}$ to $80^{\circ} \mathrm{N}$ that corresponds respectively to the latitudes of the southernmost and northernmost TCCON sites. Figure 11c shows a very distinctive behaviour between the two periods of the TANSO experiment (version v. 1 of the data before October 2011 and version v.2.0 after) in terms of difference against the TCCON data. This comes from the change in the a priori profile and averaging kernel information between the two versions of the product, $\mathrm{xCH}_{4}$ being similar in the two versions. Due to this, we split the discussion of the comparison with the TCCON data into the period before October 2011 and after October 2011.

\section{Period before October 2011}

The initial condition of all the experiments comes from the methane analysis of the DM, which is known to have a negative bias of about $20 \mathrm{ppb}$ in terms of total column when compared to independent measurements (Massart et al., 2013).
Therefore, at the beginning of the period, the FREE experiment underestimates $\mathrm{xCH}_{4}$ when compared to the measurements of the selected TCCON stations (black lines of Fig. 10). The underestimation varies from 10 to $30 \mathrm{ppb}$, depending on the station. We previously described an increase over time in $\mathrm{xCH}_{4}$ in this experiment (Sect. 3.1 and Fig. 5a). This increase allows one to reduce the difference with the TCCON measurements after the first few months and leads to a global underestimation of about $5.5 \mathrm{ppb}$ on average between November 2010 and October 2011 (Table 3) that is consistent with the global underestimation found in the comparison with the HIPPO data ( $5 \mathrm{ppb}$ ). The increase is larger in the Northern Hemisphere and the FREE experiment starts to overestimate $\mathrm{xCH}_{4}$ from March to August 2011 (Fig. 11a and black lines of the last four panels of Fig. 10). This is again consistent with the comparison against the HIPPO data for which the difference between the FREE experiment and the evaluation data was significantly contrasting between the two first campaigns (end of June to mid-July) and the two last (mid-August to mid-September). The standard deviation of the difference between the FREE experiment and the 
Table 3. Average difference (in ppb) between the free run or the analyses and the TCCON data. The average is computed for all available TCCON stations and split into regions as for Table 1 and into periods: from November 2010 to April 2012 (top block), before October 2011 (middle block) and after October 2011 (bottom block).

\begin{tabular}{lrrrr}
\hline & NH & Trop & SH & Global \\
\hline FREE & 1.19 & -6.61 & -7.60 & -1.22 \\
SCIA & -26.53 & -28.88 & -30.34 & -27.50 \\
TANSO & -8.34 & -3.11 & -3.90 & -7.04 \\
TANSO+IASI & -11.05 & 2.28 & -3.92 & -8.61 \\
\hline Before Oct 2011 & & & & \\
\hline FREE & -2.79 & -16.04 & -12.67 & -5.52 \\
SCIA & -27.50 & -30.43 & -30.35 & -28.24 \\
TANSO v.1 & -16.67 & -10.97 & -8.65 & -14.71 \\
TANSO v.1+IASI & -17.74 & 1.49 & -6.07 & -14.33 \\
\hline After Oct 2011 & & & & \\
\hline FREE & 7.03 & 0.12 & -1.00 & 4.62 \\
SCIA & -25.09 & -27.76 & -30.33 & -26.49 \\
TANSO v.2.0 & 3.91 & 2.42 & 2.26 & 3.41 \\
TANSO v.2.0+IASI & -1.19 & 2.85 & -1.09 & -0.79 \\
\hline
\end{tabular}

TCCON data also increases in the first few months (figure not shown) to reach an average value of $8 \mathrm{ppb}$ (Table 4). This value is much lower than the one obtained when compared against the HIPPO data (14 ppb).

The assimilation of the version v. 1 of the TANSO data or the SCIAMACHY data globally results in increasing the underestimation respectively up to $15 \mathrm{ppb}$ or $28 \mathrm{ppb}$ with respect to the TCCON measurements (Table 3). These underestimations are lower during the winter and increase in spring for both experiments and in summer for the TANSO experiment (Fig. 11b and c). The values of the underestimation are consistent with the values found in the comparison with the HIPPO data. The error in the north-south gradient is close to zero for the SCIA experiment, similar to the value found with the HIPPO data (Tables 1 and 3). The error is higher for the TANSO experiment but less pronounced than the one found with the HIPPO data. The TANSO experiment has an increased underestimation starting from March 2011, similar to the one of the SCIAMACHY experiment (Fig. 11c and four last panels of Fig. 10, cyan - TANSO - and green SCIA - lines). This suggests a larger latitude-dependent bias in the TANSO experiment compared to the SCIA one. The standard deviation of the differences between the experiment and the TCCON data are similar for the TANSO and SCIA experiments, with a value just lower than $6 \mathrm{ppb}$, more than 2 ppb less than for the FREE experiment (Table 4). As for the FREE experiment, the error is lower in the tropics.

The effect of the assimilation of IASI data combined with TANSO data was found to be mainly located in the tropical
Table 4. Same as Table 3 but for the standard deviation.

\begin{tabular}{lrrrr}
\hline & NH & Trop & SH & Global \\
\hline FREE & 9.04 & 4.37 & 6.63 & 8.20 \\
SCIA & 6.69 & 3.96 & 4.61 & 6.06 \\
TANSO & 6.14 & 3.60 & 4.49 & 5.61 \\
TANSO+IASI & 6.51 & 5.20 & 5.13 & 6.12 \\
\hline Before Oct 2011 & & & & \\
\hline FREE & 8.26 & 4.14 & 7.60 & 7.92 \\
SCIA & 6.20 & 3.24 & 5.15 & 5.84 \\
TANSO v.1 & 5.72 & 3.61 & 5.08 & 5.48 \\
TANSO v.1+IASI & 5.87 & 4.63 & 5.75 & 5.79 \\
\hline After Oct 2011 & & & & \\
\hline FREE & 10.18 & 4.52 & 5.35 & 8.59 \\
SCIA & 7.41 & 4.48 & 3.91 & 6.36 \\
TANSO v.2.0 & 6.75 & 3.60 & 3.73 & 5.79 \\
TANSO v.2.0+IASI & 7.45 & 5.61 & 4.32 & 6.59 \\
\hline
\end{tabular}

band where the IASI data are available (Fig. 5). When the IASI+TANSO analysis (red lines of Fig. 10) is compared to the measurements from stations situated north of $20^{\circ} \mathrm{N}$ (Park Falls, Garmisch, Karlsruhe and Sodankyla) there is hardly any significant difference with the TANSO analysis. On average over all the stations of the Northern Hemisphere, the difference is slightly increased by one ppb with the assimilation of the IASI data (Table 3). In contrast, for the stations situated south of $20^{\circ} \mathrm{S}$ (Lauder and Wollongong), IASI has a positive impact as the underestimation of the IASI+TANSO experiment $(6 \mathrm{ppb})$ is lower than for the TANSO experiment $(9 \mathrm{ppb})$ and the FREE experiment (13 ppb). In the tropical region, the statistics are influenced by the behaviour of the experiment at the Darwin station. There, the IASI+TANSO experiment slightly overestimates $\mathrm{xCH}_{4}$ during DJF 2010/2011 (red and green lines, Darwin panel, Fig. 10). This is related to the previously discussed increase of the methane column in the IASI+TANSO experiment during this period (Sect. 3.4). On average in this region, the effect of adding the IASI data in the assimilation system is positive and leads to an overestimation just above $1 \mathrm{ppb}$. The improvement due to IASI is effective only during the winter period. Then IASI seems unable to counterbalance the higher bias found in the TANSO experiment from March 2011 (Fig. 11c and d). Overall the standard deviation of the differences between the IASI+TANSO experiment and the TCCON data is sightly larger than the one of the TANSO analysis, enhanced in the tropics where the error is further increased and reaches about $1 \mathrm{ppb}$.

\section{Period after October 2011}

During the period between SON 2011 and DJF 2011/2012, the underestimation of the FREE experiment continuously 
decreases (Fig. 11a) and leads to an overestimation of $5 \mathrm{ppb}$ on average (Table 3 ). The behaviour of the SCIA experiment is the same as for the previous period. The TANSO experiment presents a contrasting behaviour due to the change of version of the assimilated product in October 2011. While the analysis underestimates $\mathrm{xCH}_{4}$ in September 2011 by almost 20 ppb for example at Park Falls, it only slightly overestimates it by $5 \mathrm{ppb}$ in October 2011 and later (green line of Park Falls panel, Fig. 10). The same behaviour can be observed for the other selected stations of the Northern Hemisphere (Fig. 11c). On average over the Northern Hemisphere, assimilating version v. 1 of the TANSO product is conducive to an underestimation of $\mathrm{xCH}_{4}$ by about $17 \mathrm{ppb}$, whereas assimilating version v.2.0 of the data is conducive to an overestimation of $4 \mathrm{ppb}$. We have a similar picture for the other regions.

Compared to the previous period with version v. 1 of the TANSO data, the benefit of the IASI data is here more persistent over the period. There is an unexpectedly positive impact at mid-latitudes, north of $20^{\circ} \mathrm{N}$ and south of $20^{\circ} \mathrm{S}$. At the end, the IASI+TANSO experiment globally underestimates the $\mathrm{xCH}_{4}$ by just less than $1 \mathrm{ppb}$. As for the previous period, the error is slightly increased on average with respect to the TANSO experiment but still much lower than the error of the FREE experiment.

\section{Whole period}

The TANSO experiment and accordingly the IASI+TANSO experiment showed very different behaviour before and after October 2011. Their statistics over the whole period are therefore not relevant. The FREE experiment was also different during the two periods. It shows a constant characteristic, which is a wrong north-south gradient with an error between 8 and $10 \mathrm{ppb}$. The statistics of the SCIA experiment are constant over time, with a global underestimation of $27 \mathrm{ppb}$ which is consistent but lower compared to the value of $37 \mathrm{ppb}$ found by Houweling et al. (2014) for 2009 when they directly compared the SCIAMACHY data with the TCCON ones.

The standard deviation of the differences between the FREE experiment and the TCCON data marginally increases from the first period to the second one. The error is always lower in the tropics, almost half the error found in the Northern Hemisphere. The value of the error for the Southern Hemisphere is between the value for the Northern Hemisphere and for the tropics. The error of the SCIA experiment has similar behaviour, but not for the second period, where the error for the Southern Hemisphere is lower than the error for the tropics. Overall, the average error is always lower than that of the FREE experiment.

\section{Conclusions}

After the loss of Envisat in April 2012, the MACC-II delayed-mode system for methane had to rely on the assimilation of the TANSO and the IASI products. In order to assess the impact of this change in the observing system, we have documented how the assimilation of the products of each of these instruments constrains the model. First, the model without any assimilation of methane data showed a good behaviour even if the initial condition was negatively biased. It nevertheless overestimates the inter-hemispheric gradient in June and July 2011 when compared to the HIPPO aircraft measurements. This was due to an underestimation of the methane concentration in the Southern Hemisphere and an overestimation in the Northern Hemisphere, the difference between them being $15 \mathrm{ppb}$. This was confirmed when the experiment was compared against measurements from the TCCON network but with a value of $10 \mathrm{ppb}$. The $\mathrm{CH}_{4}$ sources and sinks are climatological in the model and their sum produces a positive global budget. As a consequence, the free run model will have the same positive methane growth each year and therefore it will deviate from the observed growth. Using data assimilation is thus needed in order to monitor atmospheric $\mathrm{CH}_{4}$ properly.

SCIAMACHY provided dense and global measurements but only during daylight hours. This limited the number of data to assimilate, especially during the winter period of each hemisphere. When the data were available, the largest impact of the assimilation of the SCIAMACHY data was found during MAM and JJA at high latitudes in the Northern Hemisphere. There the assimilation decreased the methane concentration from the surface up to $50 \mathrm{hPa}$. This improved the north-south gradient in the analysis. On the other hand, this also produced a global underestimation of $35 \mathrm{ppb}$ for the tropospheric $\mathrm{CH}_{4}$ concentration when compared to HIPPO data and $28 \mathrm{ppb}$ for the column when compared to TCCON measurements. These estimations of the SCIAMACHY bias are in good agreement with the value of $37 \mathrm{ppb}$ found by the study of Houweling et al. (2014). In the context of the DM system, the bias of the assimilated product could not be computed as there are not enough independent data in the required time frame to anchor a bias correction scheme. For this reason, the SCIAMACHY product as the other products have not been bias corrected in this study. However, if the same version of the satellite products has to be assimilated again in the future for a reanalysis purpose, a bias correction would therefore have to be envisaged.

TANSO also provides measurements only during daylight hours, but compared to SCIAMACHY, the data are much less dense (about 3 times less) and cover only land in version v. 1 of the used product and partially the ocean in version v.2.0. Over land, the density of the TANSO data is nevertheless sufficient to produce a similar constraint on the analysis as the SCIAMACHY data owing to the background error correlations. Over tropical oceans, the density 
of SCIAMACHY data was too low to affect the analysis and to have any appreciable difference compared to TANSO. The change of version for the TANSO product had a significant impact on the analysis. While the analysis of the first version presented an underestimation of $15 \mathrm{ppb}$ on average compared to the measurements from the TCCON network, the analysis of the second version presents an overestimation of only $3 \mathrm{ppb}$. The underestimation of the first analysis is confirmed by the comparison with the measurements from the HIPPO campaigns that produced a value of $18 \mathrm{ppb}$ on the tropospheric $\mathrm{CH}_{4}$ concentration. For both comparisons (TC$\mathrm{CON}$ and HIPPO), the biggest part of the underestimation lies in the Northern Hemisphere and the comparisons suggest a latitude-dependent bias in the data. For version v.2.0 of the TANSO data, the comparison with the TCCON data suggests a more constant bias in time of about $3 \mathrm{ppb}$, but is still latitude dependent. Part of this bias could be explained by the use of prior $\mathrm{CO}_{2}$ concentrations derived from CarbonTracker in the proxy retrievals. This will shortly be evaluated using the $\mathrm{CO}_{2}$ MACC-II forecast instead of an extrapolation of the CarbonTracker $\mathrm{CO}_{2}$ product.

IASI has a completely different design than the two other instruments, as it measures in the thermal infrared. It provides data during day and night, over land and ocean, and with a very high spatial density. The measurements provide information in the middle troposphere, while the other instruments are more sensitive to the lower troposphere, but only data situated in a large tropical belt are currently assimilated. The data in this region are expected to have a higher quality than the data at high latitudes. In this paper, the IASI data are assimilated together with the TANSO data. The resulting experiment was found to be different for the first four seasons compared to the last two, which is likely due to the change in the version of the TANSO product. During the first period, we showed an increase in the methane concentration mainly in the middle troposphere and over the tropics due to the assimilation of the IASI data. The impact was found mainly during the winter and led to a better agreement with the TCCON data over the tropics with an averaged difference of $1.5 \mathrm{ppb}$, while the difference was $-11 \mathrm{ppb}$ for the TANSO experiment. During the summer, the middle tropospheric increase was smaller and did not change the methane profile much on average. On the other hand, the variability was increased from $8 \mathrm{ppb}$ (TANSO experiment) to $12 \mathrm{ppb}$ (IASI+TANSO experiment) in the tropics when compared to the HIPPO data. The increase is not as pronounced when compared to the TCCON measurement (1 ppb). After the change in the version of the assimilated TANSO data, the impact of the IASI data on the methane profile changed considerably. Unfortunately we do not have profiles of independent measurements to evaluate the change in the profile of the analysis. In terms of total column the impact of the IASI data was positive during the whole period, providing a low biased analysis with an error between 4 and 7 ppb depending on the region.
The combination of the IASI data and version v. 2.0 of the TANSO data has been shown to be a good candidate for continuing the monitoring of the tropospheric methane in the MACC-II system. Despite residual biases present in the products, the main concern is the deficiency of the data to constrain the system south of $45^{\circ} \mathrm{S}$ and north of $45^{\circ} \mathrm{N}$ in winter or $80^{\circ} \mathrm{N}$ in summer, this last region also being not observed by SCIAMACHY. Extending the coverage of the IASI $\mathrm{CH}_{4}$ data to the extra-tropical regions could help by increasing the number of data points in these regions.

Acknowledgements. This study was funded by the European Commission under the EU Seventh Research Framework Programme (grant agreement no. 283576, MACC II). TCCON data were obtained from the TCCON Data Archive, operated by the California Institute of Technology from the website at http://tccon.ipac.caltech.edu/. The HIPPO program was supported by NSF grants ATM-0628575, ATM-0628519, and ATM-0628388 to Harvard University, University of California (San Diego), and by University Corporation for Atmospheric Research, University of Colorado/CIRES, by the NCAR and by the NOAA Earth System Research Laboratory. A. Butz is supported by Deutsche Forschungsgemeinschaft (DFG) through the Emmy-Noether programme, grant BU2599/1-1 (RemoteC). The authors are grateful to Marijana Crepulja and Martin Suttie for the processing of the satellite data used in this study.

Edited by: W. Lahoz

\section{References}

Bergamaschi, P., Frankenberg, C., Meirink, J. F., Krol, M., Dentener, F., Wagner, T., Platt, U., Kaplan, J. O., Körner, S., Heimann, M., Dlugokencky, E. J., and Goede, A.: Satellite chartography of atmospheric methane from SCIAMACHY on board ENVISAT: 2. Evaluation based on inverse model simulations, J. Geophys. Res., 112, D02304, doi:10.1029/2006JD007268, 2007.

Bergamaschi, P., Frankenberg, C., Meirink, J. F., Krol, M., Villani, M. G., Houweling, S., Dentener, F., Dlugokencky, E. J., Miller, J. B., Gatti, L. V., Engel, A., and Levin, I.: Inverse modeling of global and regional $\mathrm{CH}_{4}$ emissions using SCIAMACHY satellite retrievals, J. Geophys. Res., 114, D22301, doi:10.1029/2009JD012287, 2009.

Butz, A., Hasekamp, O. P., Frankenberg, C., Vidot, J., and Aben, I.: $\mathrm{CH}_{4}$ retrievals from space-based solar backscatter measurements: performance evaluation against simulated aerosol and cirrus loaded scenes, J. Geophys. Res., 115, D24302, doi:10.1029/2010JD014514, 2010.

Crevoisier, C., Nobileau, D., Fiore, A. M., Armante, R., Chédin, A., and Scott, N. A.: Tropospheric methane in the tropics - first year from IASI hyperspectral infrared observations, Atmos. Chem. Phys., 9, 6337-6350, doi:10.5194/acp-9-6337-2009, 2009.

Crevoisier, C., Nobileau, D., Armante, R., Crépeau, L., Machida, T., Sawa, Y., Matsueda, H., Schuck, T., Thonat, T., Pernin, J., Scott, N. A., and Chédin, A.: The 2007-2011 evolution of tropical methane in the mid-troposphere as seen from space 
by MetOp-A/IASI, Atmos. Chem. Phys., 13, 4279-4289, doi:10.5194/acp-13-4279-2013, 2013.

Daley, R.: Estimating the wind field from chemical constituent observations: experiments with a one-dimensional extended Kalman filter, Mon. Weather Rev., 123, 181-198, 1995.

Dlugokencky, E. J., Bruhwiler, L., White, J. W. C., Emmons, L. K., Novelli, P. C., Montzka, S. A., Masarie, K. A., Lang, P. M., Crotwell, A. M., Miller, J. B., and Gatti, L. V.: Observational constraints on recent increases in the atmospheric $\mathrm{CH}_{4}$ burden, Geophys. Res. Lett., 36, L18803, doi:10.1029/2009GL039780, 2009.

Engelen, R. J. and Bauer, P.: The use of variable $\mathrm{CO}_{2}$ in the data assimilation of AIRS and IASI radiances, Q. J. Roy. Meteor. Soc., 140, 958-965, doi:10.1002/qj.919, 2014.

Etheridge, D., Pearman, G., and Fraser, P.: Changes in tropospheric methane between 1841 and 1978 from a high accumulation rate Antarctic ice core, Tellus B, 44, 282-294, 1992.

Farman, J. C., Gardiner, B. G., and Shanklin, J. D.: Large losses of total ozone in Antarctica reveal seasonal $\mathrm{ClO}_{\mathrm{X}} / \mathrm{NO}_{\mathrm{x}}$ interaction, Nature, 315, 207-210, doi:10.1038/315207a0, 1985.

Frankenberg, C., Platt, U., and Wagner, T.: Iterative maximum a posteriori (IMAP)-DOAS for retrieval of strongly absorbing trace gases: Model studies for $\mathrm{CH}_{4}$ and $\mathrm{CO}_{2}$ retrieval from near infrared spectra of SCIAMACHY onboard ENVISAT, Atmos. Chem. Phys., 5, 9-22, doi:10.5194/acp-5-9-2005, 2005.

Frankenberg, C., Aben, I., Bergamaschi, P., Dlugokencky, E. J., van Hees, R., Houweling, S., van der Meer, P., Snel, R., and Tol, P.: Global column-averaged methane mixing ratios from 2003 to 2009 as derived from SCIAMACHY: trends and variability, J. Geophys. Res., 116, D04302, doi:10.1029/2010JD014849, 2011.

Gloudemans, A. M. S., Schrijver, H., Hasekamp, O. P., and Aben, I.: Error analysis for $\mathrm{CO}$ and $\mathrm{CH}_{4}$ total column retrievals from SCIAMACHY $2.3 \mu \mathrm{m}$ spectra, Atmos. Chem. Phys., 8, 39994017, doi:10.5194/acp-8-3999-2008, 2008.

Houweling, S., Kaminski, T., Dentener, F., Lelieveld, J., and Heimann, M.: Inverse modeling of methane sources and sinks using the adjoint of a global transport model, J. Geophys. Res., 104, 26137-26160, doi:10.1029/1999JD900428, 1999.

Houweling, S., Krol, M., Bergamaschi, P., Frankenberg, C., Dlugokencky, E. J., Morino, I., Notholt, J., Sherlock, V., Wunch, D., Beck, V., Gerbig, C., Chen, H., Kort, E. A., Röckmann, T., and Aben, I.: A multi-year methane inversion using SCIAMACHY, accounting for systematic errors using TCCON measurements, Atmos. Chem. Phys., 14, 3991-4012, doi:10.5194/acp-14-39912014, 2014.

Janssens-Maenhout, G., Dentener, F., Aardenne, J. V., Monni, S., Pagliari, V., Orlandini, L., Klimont, Z., Kurokawa, J., Akimoto, H., Ohara, T., Wankmueller, R., Battye, B., Grano, D., Zuber, A., and Keating, T.: EDGAR-HTAP: a Harmonized Gridded Air Pollution Emission Dataset Based on National Inventories, JRC68434, EUR report No EUR 25 299-2012, ISBN 978-92-7923122-0, ISSN 1831-9424, European Commission Publications Office, Ispra (Italy), 2012

Kaiser, J. W., Heil, A., Andreae, M. O., Benedetti, A., Chubarova, N., Jones, L., Morcrette, J.-J., Razinger, M., Schultz, M. G., Suttie, M., and van der Werf, G. R.: Biomass burning emissions estimated with a global fire assimilation system based on observed fire radiative power, Biogeosciences, 9, 527-554, doi:10.5194/bg-9-527-2012, 2012.
Kirschke, S., Bousquet, P., Ciais, P., Saunois, M., Canadell, J. G., Dlugokencky, E. J., Bergamaschi, P., Bergmann, D., Blake, D. R., Bruhwiler, L., Cameron-Smith, P., Castaldi, S., Chevallier, F., Feng, L., Fraser, A., Heimann, M., Hodson, E. L., Houweling, S., Josse, B., Fraser, P. J., Krummel, P. B., Lamarque, J.-F., Langenfelds, R. L., Quéré, C. L., Naik, V., O’Doherty, S., Palmer, P. I., Pison, I., Plummer, D., Poulter, B., Prinn, R. G., Rigby, M., Ringeval, B., Santini, M., Schmidt, M., Shindell, D. T., Simpson, I. J., Spahni, R., Steele, L. P., Strode, S. A., Sudo, K., Szopa, S., van der Werf, G. R., Voulgarakis, A., van Weele, M., Weiss, R. F., Williams, J. E., and Zeng, G.: Three decades of global methane sources and sinks, Nat. Geosci., 6, 813-823, doi:10.1038/ngeo1955, 2013.

Kleipool, Q., Jongma, R., Gloudemans, A., Schrijver, H., Lichtenberg, G., van Hees, R., Maurellis, A., and Hoogeveen, R.: In-flight proton-induced radiation damage to SCIAMACHY's extended-wavelength InGaAs near-infrared detectors, Infrared Phys. Techn., 50, 30-37, 2007.

Krol, M., Houweling, S., Bregman, B., van den Broek, M., Segers, A., van Velthoven, P., Peters, W., Dentener, F., and Bergamaschi, P.: The two-way nested global chemistry-transport zoom model TM5: algorithm and applications, Atmos. Chem. Phys., 5, 417-432, doi:10.5194/acp-5-417-2005, 2005.

Lahoz, W. A., Geer, A. J., Bekki, S., Bormann, N., Ceccherini, S., Elbern, H., Errera, Q., Eskes, H. J., Fonteyn, D., Jackson, D. R., Khattatov, B., Marchand, M., Massart, S., Peuch, V.H., Rharmili, S., Ridolfi, M., Segers, A., Talagrand, O., Thornton, H. E., Vik, A. F., and von Clarmann, T.: The Assimilation of Envisat data (ASSET) project, Atmos. Chem. Phys., 7, 17731796, doi:10.5194/acp-7-1773-2007, 2007.

Lambert, G. and Schmidt, S.: Reevaluation of the oceanic flux of methane: uncertainties and long term variations, Chemosph. Global Change Sci., 26, 579-589, 1993.

Massart, S., Agusti-Panareda, A., and Engelen, R.: Quality of the analysed $\mathrm{CH}_{4}$ 4-D fields from the MACC-II delayed mode system, MACC-II delivrable D_042.05, ECMWF, available at: http://www.copernicus-atmosphere.eu/documents/maccii/ deliverables/ghg/MACCII_GHG_DEL_D42.5_20130125_ ECMWF.pdf, 2013.

Matthews, E., Fung, I., and Lerner, J.: Methane emission from rice cultivation: geographic and seasonal distribution of cultivated areas and emissions, Global Biogeochem. Cy., 5, 3-24, doi:10.1029/90GB02311, 1991.

McPeters, R. and Labow, G.: An assessment of the accuracy of 14.5 years of Nimbus 7 TOMS version 7 ozone data by comparison with the Dobson network, Geophys. Res. Lett., 23, 3695-3698, 1996.

Myhre, G., Shindell, D., Bréon, F.-M., Collins, W., Fuglestvedt, J., Huang, J., Koch, D., Lamarque, J.-F., Lee, D., Mendoza, B., Nakajima, T., Robock, A., Stephens, G., Takemura, T., and Zhang, H.: Anthropogenic and Natural Radiative Forcing, in: Climate Change 2013: The Physical Science Basis. Contribution of Working Group I to the Fifth Assessment Report of the Intergovernmental Panel on Climate Change, edited by: Stocker, T. F., Qin, D., Plattner, G.-K., Tignor, M., Allen, S. K., Boschung, J., Nauels, A., Xia, Y., Bex, V., and Midgley, P. M., Cambridge University Press, Cambridge, United Kingdom and New York, NY, USA, 659-740, 2013. 
Parker, R., Boesch, H., Cogan, A., Fraser, A., Feng, L., Palmer, P., Messerschmidt, J., Deutscher, N., Griffith, D. W. T., Notholt, J., Wennberg, P. O., and Wunch, D.: Methane observations from the greenhouse gases observing satellite: comparison to groundbased TCCON data and model calculations, Geophys. Res. Lett., 38, L15807, doi:10.1029/2011GL047871, 2011.

Parrish, D. and Derber, J.: National Meteorological Center's spectral statistical interpolation analysis system, Mon. Weather. Rev., 120, 1747-1763, 1992.

Ridgwell, A. J., Marshall, S. J., and Gregson, K.: Consumption of atmospheric methane by soils: a process-based model, Global Biogeochem. Cy., 13, 59-70, doi:10.1029/1998GB900004, 1999.

Sanderson, M. G.: Biomass of termites and their emissions of methane and carbon dioxide: a global database, Global Biogeochem. Cy., 10, 543-557, doi:10.1029/96GB01893, 1996.

Schepers, D., Guerlet, S., Butz, A., Landgraf, J., Frankenberg, C., Hasekamp, O., Blavier, J.-F., Deutscher, N., Griffith, D., Hase, F., Kyro, E., Morino, I., Sherlock, V., Sussmann, R., and Aben, I.: Methane retrievals from Greenhouse Gases Observing Satellite (GOSAT) shortwave infrared measurements: performance comparison of proxy and physics retrieval algorithms, J. Geophys. Res., 117, D10307, doi:10.1029/2012JD017549, 2012.

Spahni, R., Chappellaz, J., Stocker, T. F., Loulergue, L., Hausammann, G., Kawamura, K., Flückiger, J., Schwander, J., Raynaud, D., Masson-Delmotte, V., and Jouzel, J.: Atmospheric methane and nitrous oxide of the late pleistocene from Antarctic ice cores, Science, 310, 1317-1321, doi:10.1126/science.1120132, 2005.

WMO: Greenhouse Gas Bulletin, The State of Greenhouse Gases in the Atmosphere Based on Global Observations through 2011, World Meteorological Organization, Geneva, Switzerland, available at: http://www.wmo.int/pages/prog/arep/gaw/ ghg/documents/GHG_Bulletin_No.8_en.pdf, 8, 2012.
Wofsy, S. C., the HIPPO Science Team, Cooperating Modellers, and Satellite Teams: HIAPER Pole-to-Pole Observations (HIPPO): fine-grained, global-scale measurements of climatically important atmospheric gases and aerosols, Philos. T. Roy. Soc. A, 369, 2073-2086, doi:10.1098/rsta.2010.0313, 2011.

Wofsy, S. C., Daube, B. C., Jimenez, R., Kort, E., Pittman, J. V., Park, S., Commane, R., Xiang, B., Santoni, G., Jacob, D., Fisher, J., Pickett-Heaps, C., Wang, H., Wecht, K., Wang, Q.Q., Stephens, B. B., Shertz, S., Watt, A., Romashkin, P., Campos, T., Haggerty, J., Cooper, W. A., Rogers, D., Beaton, S., Hendershot, R., Elkins, J. W., Fahey, D. W., Gao, R. S., Moore, F. Montzka, S. A., Schwarz, J. P., Perring, A. E., Hurst, D., Miller, B. R., Sweeney, C., Oltmans, S., Nance, D., Hintsa, E., Dutton, G., Watts, L. A., Spackman, J. R., Rosenlof, K. H., Ray, E. A., Hall, B., Zondlo, M. A., Diao, M., Keeling, R., Bent, J., Atlas, E. L., Lueb, R., and Mahoney, M. J.: HIPPO Merged 10s Meteorology, Atmospheric Chemistry, Aerosol Data, Tech. Rep. Release 20121129, Carbon Dioxide Information Analysis Center, Oak Ridge National Laboratory, Oak Ridge, Tennessee, USA, doi:10.3334/CDIAC/hippo_010, 2012.

Wunch, D., Toon, G., Blavier, J.-F., Washenfelder, R., Notholt, J., Connor, B., Griffith, D., Sherlock, V., and Wennberg, P.: The total carbon column observing network, Philos. T. Roy. Soc. A, 369, 1885-1890, doi:10.1098/rsta.2010.0240, 2011.

Yoshida, Y., Kikuchi, N., Morino, I., Uchino, O., Oshchepkov, S., Bril, A., Saeki, T., Schutgens, N., Toon, G. C. Wunch, D., Roehl, C. M., Wennberg, P. O., Griffith, D. W. T., Deutscher, N. M., Warneke, T., Notholt, J., Robinson, J., Sherlock, V., Connor, B., Rettinger, M., Sussmann, R., Ahonen, P., Heikkinen, P., Kyrö, E., Mendonca, J., Strong, K., Hase, F., Dohe, S., and Yokota, T.: Improvement of the retrieval algorithm for GOSAT SWIR $\mathrm{XCO}_{2}$ and $\mathrm{XCH}_{4}$ and their validation using TCCON data, Atmos. Meas. Tech., 6, 1533-1547, doi:10.5194/amt-6-1533-2013, 2013. 